\title{
Calibration and field testing of cavity ring-down laser spectrometers measuring $\mathrm{CH}_{4}, \mathrm{CO}_{2}$, and $\delta^{13} \mathrm{CH}_{4}$ deployed on towers in the Marcellus Shale region
}

\author{
Natasha L. Miles ${ }^{1}$, Douglas K. Martins ${ }^{1, \text { a }}$, Scott J. Richardson ${ }^{1}$, Christopher W. Rella ${ }^{2}$, Caleb Arata ${ }^{2,3}$, \\ Thomas Lauvaux $^{1}$, Kenneth J. Davis ${ }^{1}$, Zachary R. Barkley ${ }^{1}$, Kathryn McKain ${ }^{4}$, and Colm Sweeney ${ }^{4}$ \\ ${ }^{1}$ Department of Meteorology and Atmospheric Science, The Pennsylvania State University, University Park, \\ Pennsylvania 16802, USA \\ ${ }^{2}$ Picarro, Inc., Santa Clara, California 95054, USA \\ ${ }^{3}$ Department of Environmental Science, Policy, and Management, University of California, Berkeley, California 94720, USA \\ ${ }^{4}$ National Oceanic and Atmospheric Administration, University of Colorado, Boulder, Colorado 80305, USA \\ a current address: FLIR Systems, Inc., West Lafayette, Indiana 47906, USA
}

Correspondence: Natasha L. Miles (nmiles@psu.edu)

Received: 3 October 2017 - Discussion started: 16 October 2017

Revised: 23 January 2018 - Accepted: 28 January 2018 - Published: 5 March 2018

\begin{abstract}
Four in situ cavity ring-down spectrometers (G2132-i, Picarro, Inc.) measuring methane dry mole fraction $\left(\mathrm{CH}_{4}\right)$, carbon dioxide dry mole fraction $\left(\mathrm{CO}_{2}\right)$, and the isotopic ratio of methane $\left(\delta^{13} \mathrm{CH}_{4}\right)$ were deployed at four towers in the Marcellus Shale natural gas extraction region of Pennsylvania. In this paper, we describe laboratory and field calibration of the analyzers for tower-based applications and characterize their performance in the field for the period January-December 2016. Prior to deployment, each analyzer was tested using bottles with various isotopic ratios, from biogenic to thermogenic source values, which were diluted to varying degrees in zero air, and an initial calibration was performed. Furthermore, at each tower location, three field tanks were employed, from ambient to high mole fractions, with various isotopic ratios. Two of these tanks were used to adjust the calibration of the analyzers on a daily basis. We also corrected for the cross-interference from ethane on the isotopic ratio of methane. Using an independent field tank for evaluation, the standard deviation of $4 \mathrm{~h}$ means of the isotopic ratio of methane difference from the known value was found to be $0.26 \% \circ \delta^{13} \mathrm{CH}_{4}$. Following improvements in the field tank testing scheme, the standard deviation of $4 \mathrm{~h}$ means was $0.11 \%$, well within the target compatibility of $0.2 \%$. Round-robin style testing using tanks with near-ambient isotopic ratios indicated mean errors of -0.14 to $0.03 \%$ for each of the analyzers. Flask to in situ comparisons showed
\end{abstract}

mean differences over the year of 0.02 and $0.08 \%$, for the east and south towers, respectively.

Regional sources in this region were difficult to differentiate from strong perturbations in the background. During the afternoon hours, the median differences of the isotopic ratio measured at three of the towers, compared to the background tower, were -0.15 to $0.12 \%$ o with standard deviations of the $10 \mathrm{~min}$ isotopic ratio differences of $0.8 \%$. In terms of source attribution, analyzer compatibility of $0.2 \% o \delta^{13} \mathrm{CH}_{4}$ affords the ability to distinguish a $50 \mathrm{ppb} \mathrm{CH}_{4}$ peak from a biogenic source (at $-60 \%$, for example) from one originating from a thermogenic source $(-35 \%$ ), with the exact value dependent upon the source isotopic ratios. Using a Keeling plot approach for the non-afternoon data at a tower in the center of the study region, we determined the source isotopic signature to be $-31.2 \pm 1.9 \%$, within the wide range of values consistent with a deep-layer Marcellus natural gas source. 


\section{Introduction}

uantification of regional greenhouse gas emissions resulting from natural gas extraction activities is critical for determination of the climate effects of natural gas usage compared to coal or oil. Studies have shown that the emission rates as a percentage of production vary significantly from reservoir to reservoir. An aircraft-based mass balance study in the Uintah basin in Utah (Karion et al., 2013; Rella et al., 2015) found a methane emission rate of $6.2-11.7 \%$ of production, exceeding the $3.2 \%$ threshold for natural gas climate benefits compared to coal determined by Alvarez et al. (2012). In the Denver-Julesburg basin in Colorado, Pétron et al. (2014) found an emissions rate of $4 \%$ of production, again using an aircraft mass balance approach. The Barnett Shale, one of the largest production basins in the United States with $8 \%$ of total US natural gas production, was found to exhibit a lower emission rate of 1.3-1.9\% (Karion et al., 2015). Using a model optimization approach for aircraft data, Barkley et al. (2017) found the weighted mean emission rate from unconventional natural gas production and gathering facilities in the Marcellus region in northeastern Pennsylvania, a region with mostly dry natural gas, to be only $0.36 \%$ of total gas production.

Aircraft-based studies cover large areas, but the temporal coverage is limited. Tower-based networks offer a complementary approach, making continuous measurements over long periods of time. At the Boulder Atmospheric Observatory (BAO) tall tower, daily flask measurements are found to contain enhanced levels of methane and other alkanes, compared to the other tall towers in the National Oceanic and Atmospheric Administration (NOAA) network (Pétron et al., 2012). Tower measurements allow for continuous measurements in the well-mixed boundary layer which are influenced by both nearby sources and the integrated effect of the upstream emissions. While towers provide near-continuous coverage of regional emissions, specific emissions sources with specific isotopic signatures are often diluted by mixing, making the differences from background very small.

Differentiating $\mathrm{CH}_{4}$ emissions from natural gas activities from other sources (e.g., wetlands, cattle, landfills) is key to documenting the greenhouse gas impact of natural gas production and to evaluating the effectiveness of emissions reduction activities. The isotopic ratio of methane $\left(\delta^{13} \mathrm{CH}_{4}\right)$ is particularly useful in this regard (Coleman et al., 1995). In general, heavy isotope ratios are characteristic of thermogenic $\mathrm{CH}_{4}$ sources (i.e., fossil-fuel-based), and light isotope ratios are characteristic of biogenic sources (Dlugokencky et al., 2011). Schwietzke et al. (2016) compiled a comprehensive database of isotopic methane source signatures, indicating signatures of $-44.0 \%$ o for globally averaged fossil-fuel sources of methane; $-62.2 \%$ for globally averaged microbial sources such as wetlands, ruminants, and landfills; and $-22.2 \%$ for globally averaged biomass burning sources. Atmospheric measurements of $\delta^{13} \mathrm{CH}_{4}$ have been used to parti- tion emissions of $\mathrm{CH}_{4}$ into source categories (e.g., Mikaloff Fletcher et al., 2004a, b; Kai et al., 2011). It is important to note, however, that, for fossil-fuel sources of methane, isotopic ratios of methane vary significantly from reservoir to reservoir (e.g., Townsend-Small et al., 2015; Rella et al., 2015), and with depth in a single reservoir (Molofsky et al., 2011; Baldassare et al., 2014).

The isotopic ratio of methane has traditionally been measured in the laboratory with continuous-flow gas chromatography-isotope ratio mass spectrometry, with repeatability of $\pm 0.05 \%$ o (Fisher et al., 2006). Röckmann et al. (2016) recently compared continuous in situ measurements of methane isotopic ratio using a dual isotope mass spectrometric system (IRMS) and a quantum cascade laser absorption spectroscopy (QCLAS)-based technique at the Cabauw tower site in the Netherlands. They showed that high-temporal-resolution methane isotopic ratio data can be used in conjunction with a global and a mesoscale model to evaluate $\mathrm{CH}_{4}$ emission inventories. Röckmann et al. (2016) also used a moving Keeling plot approach to identify source isotopic ratios.

Cavity ring-down spectroscopy (CRDS) is another technique for measurement of continuous in situ isotopic ratio of methane (Rella et al., 2015). CRDS is a laser-based technique in which the infrared absorption loss caused by a gas in the sample cell is measured to quantify the mole fraction of the gas. The analyzers utilize three highly reflective mirrors such that the flow cell has an effective optical path length of $15-20 \mathrm{~km}$, allowing highly precise measurements. The temperature and pressure of the sample cell are tightly controlled, improving the stability of the measurements (Crosson, 2008). Rella et al. (2015) documented the operation of CRDS (Picarro, Inc., model G2132-i) analyzers, including cross-interference from other gases, and general calibration approach.

Furthermore, Rella et al. (2015) described the use of two tanks to correct for analyzer drift of the isotopic ratio measured by the G2132-i analyzers. In this approach, the variables of interest, i.e., the total methane mole fraction and the isotopic ratio, are directly calibrated. The drift terms in the calibration equations have differing dependence on mole fraction, requiring the use of at least two tanks for calibration. For this study, three field tanks were deployed at each tower location, two for the field calibration and one as an independent test.

In this paper, we describe a network of four tower-based atmospheric observation locations, measuring $\mathrm{CH}_{4}$ and $\mathrm{CO}_{2}$ dry mole fractions and $\delta^{13} \mathrm{CH}_{4}$ using CRDS (Picarro, Inc., model G2132-i) analyzers in the Marcellus Shale region in north-central Pennsylvania at towers referred to here as the north, south, east, and central towers. We focus on the specific application of tower-based measurements of isotopic methane using CRDS analyzers. Instead of describing the methods and results separately, we combine these for each topic. First, we describe laboratory calibration of the G2132-i 
analyzers, field calibration approach, and calibration results. We determine the compatibility achieved for the isotopic measurements in the current field deployment, using an independent field tank, round-robin style testing, and comparisons to flasks as our primary metrics. We also evaluate the performance of the G2132-i analyzers in terms of $\mathrm{CH}_{4}$ and $\mathrm{CO}_{2}$ mole fractions measurements by comparing to a $\mathrm{G} 2301$ analyzer. We then describe the tower locations and compare differences in $\mathrm{CH}_{4}$ mole fraction and isotopic ratio observed at the towers and use a Keeling plot approach to determine source isotopic signatures. Finally, we describe recommendations for future isotopic methane CRDS tower-based networks.

\section{Compatibility goals}

Because this is the first network of multiple methane isotopic ratio continuous analyzers to date, the needed compatibility has not yet been defined. Thus, our compatibility goals for $\mathrm{CO}_{2}$ and $\mathrm{CH}_{4}$ mole fractions follow the WMO compatibility recommendation for global studies: $0.1 \mathrm{ppm}$ for $\mathrm{CO}_{2}$ (in the Northern Hemisphere) and $2 \mathrm{ppb}$ for $\mathrm{CH}_{4}$ (GAW Report No. $229,2016)$. Here we use the term compatibility, as advised in the GAW Report No. 229 (2016), to describe the difference between two measurements, rather than the absolute accuracy of those measurements.

For $\delta^{13} \mathrm{CH}_{4}$, we set our target compatibility at $0.2 \%$, thought to be a reasonable goal based on laboratory testing prior to deployment and the results shown in Rella et al. (2015). This goal corresponds to the WMO extended compatibility goal for the isotopic ratio of methane, which was deemed sufficient for regionally focused studies with large local fluxes. The measured signal at the towers is a mixture of the source and the background (Pataki et al., 2003), and the ability to distinguish between a biogenic and thermogenic source depends on the difference of the source isotopic signature from background and the peak strength in terms of methane mole fraction. Equating the slope of a source and the background with the slope of a mixture and the background on a Keeling plot (Keeling, 1961), the measured isotopic ratio difference $(\Delta \delta)$ is given by

$\Delta \delta=\left(\delta_{\text {source }}-\delta_{\text {background }}\right) \frac{\Delta \mathrm{CH}_{4}}{\mathrm{CH}_{4, \text { measured }}}$,

where $\delta_{\text {source }}$ and $\delta_{\text {background }}$ are the isotopic ratios of the source and the background, $\mathrm{CH}_{4}$, measured is the measured methane mole fraction, and $\Delta \mathrm{CH}_{4}$ is the difference between the measured mole fraction and the background. This equation is represented graphically in Fig. 1. If there are two possible sources in a region, a biogenic source at $-60 \%$ and a thermogenic source at $-35 \%$, for example, the difference in isotopic ratio difference is at least 3 times the compatibility goal of $0.2 \%$ (and thus distinguishable) for a peak strength of $50 \mathrm{ppb} \mathrm{CH}$ or greater, assuming a measured $\mathrm{CH}_{4}$

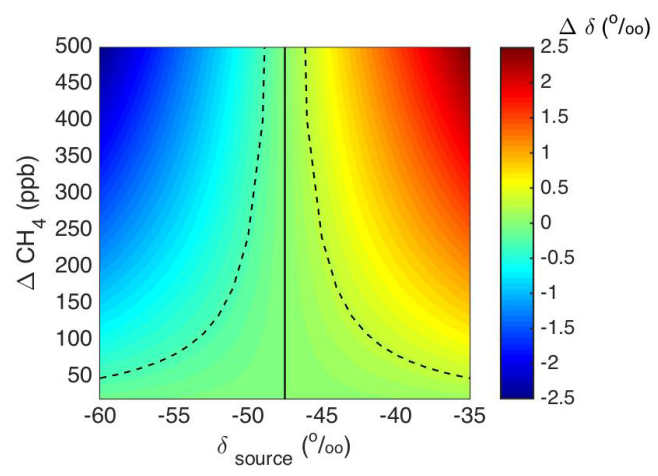

Figure 1. Isotopic ratio difference from background $(\Delta \delta)$ resulting from a mixture of background and source signatures, as a function of source isotopic ratio ( $\left.\delta_{\text {source }}\right)$ and $\mathrm{CH}_{4}$ mole fraction enhancement above background $\left(\Delta \mathrm{CH}_{4}\right)$. Here the source end-members are -60 and $-35 \%$. Background $\mathrm{CH}_{4}$ mole fraction was assumed to be $2000 \mathrm{ppb}$, and background isotopic ratio $-47.5 \%$ (vertical solid line). Dashed lines indicate -0.3 and $0.3 \%$ difference from background.

mole fraction of $2000 \mathrm{ppb}$ and a background isotopic ratio of $-47.5 \%$. In this case, the biogenic source would measure $0.3 \%$ above the background, as opposed to the thermogenic source measuring $0.3 \%$ o below the background. As shown in Fig. 1, sources closer to the background in isotopic ratio require a larger peak in $\mathrm{CH}_{4}$ and those further from the background can be attributed with a smaller peak in $\mathrm{CH}_{4}$.

\section{Allan standard deviation testing}

Allan standard deviation testing (Allan, 1966) is a useful tool for testing the noise and drift response of instrumentation. The Allan standard deviation for each averaging interval is proportional to the range of values for each averaging interval. This range typically decreases for increasing averaging interval, as the noise is reduced through averaging. As the averaging interval increases, however, analyzer drift may contribute, placing an upper bound on the optimal averaging interval. Thus, the Allan deviation results are critical for defining the minimum averaging time required for a given target compatibility.

To calculate the Allan standard deviation of the G2132$i$ analyzers used in this study, one tank containing ambient mole fractions of $\mathrm{CH}_{4}(1.9 \mathrm{ppm})$ and $\mathrm{CO}_{2}(\sim 400 \mathrm{ppm})$, and one tank containing high mole fraction of $\mathrm{CH}_{4}(9.7 \mathrm{ppm})$ and an ambient mole fraction of $\mathrm{CO}_{2}(\sim 400 \mathrm{ppm})$ were tested with an analyzer for $24 \mathrm{~h}$. For simplicity, we call these the "high" and "low" tanks, respectively, and they are described further in Sect. 5.1. We tested both as the noise is known to be less for higher mole fractions, and at least one tank with higher $\mathrm{CH}_{4}$ mole fraction is necessary for the isotopic ratio calibration (Rella et al., 2015). 

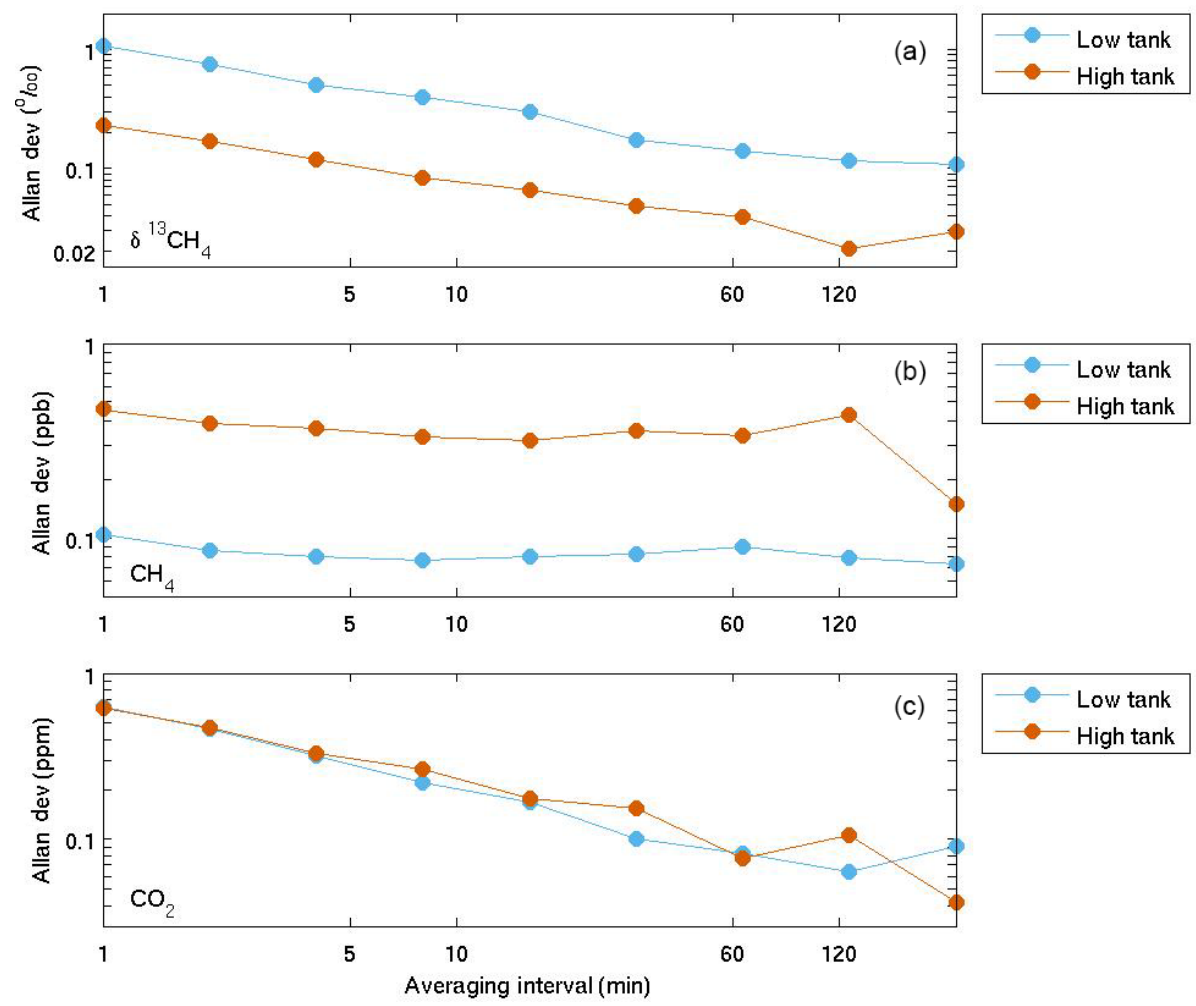

Figure 2. Allan standard deviation for (a) $\delta{ }^{13} \mathrm{CH}_{4}$, (b) $\mathrm{CH}_{4}$, and (c) $\mathrm{CO}_{2}$ for a high $\mathrm{CH}_{4}$ mole fraction tank $\left(9.7 \mathrm{ppm} \mathrm{CH}_{4}, \sim 400 \mathrm{ppm} \mathrm{CO}_{2}\right.$, $-38.3 \% \delta^{13} \mathrm{CH}_{4}$; orange) and a low (1.9 ppm $\left.\mathrm{CH}_{4}, \sim 400 \mathrm{ppm} \mathrm{CO}_{2},-23.7 \% \circ \delta^{13} \mathrm{CH}_{4}\right)$ tank (blue). The $x$ axis is truncated to focus on minimum averaging times required to achieve the desired compatibility goals.

The resulting Allan standard deviations for $\delta^{13} \mathrm{CH}_{4}, \mathrm{CH}_{4}$, and $\mathrm{CO}_{2}$ are shown in Fig. 2. For the high tank, the Allan deviation for $\delta^{13} \mathrm{CH}_{4}$ (Fig. 2a) was $<0.2 \%$ (our target compatibility) for an averaging interval of $2 \mathrm{~min}$ (the averaging interval used each field calibration cycle of the high tank). To reduce the noise to $<0.1 \%$, an averaging interval of $4 \mathrm{~min}$ is sufficient (in addition to the time required for the transition between gases). For the low tank, in order for the Allan standard deviation to be $<0.2 \%$ o, 32 min was required, and $64 \mathrm{~min}$ for $0.1 \%$ noise. Note that for much of the deployment the near-ambient mole fraction target tank was not sampled sufficiently within each day for the desired compatibility goals.

For $\mathrm{CH}_{4}$ (Fig. 2b), both the high- and low-tank Allan deviation were $<1 \mathrm{ppb}$ for even a $1 \mathrm{~min}$ averaging interval. The $\mathrm{CO}_{2}$ levels in the high and low tanks were similar $(\sim 400 \mathrm{ppm})$, and an averaging interval of 6 min corresponded to Allan standard deviations of $0.3 \mathrm{ppm}$, and $64 \mathrm{~min}$ was necessary for $0.1 \mathrm{ppm}$ (Fig. 2c). The performance of the G2132-i analyzers in terms of $\mathrm{CO}_{2}$ precision is worse than that of the G2301/G2401 analyzers primarily because a weaker spectral line is used (Rella et al., 2015).

\section{Laboratory calibration}

\subsection{Experimental setup}

Prior to field deployment, each analyzer was calibrated for $\mathrm{CH}_{4}$ and $\mathrm{CO}_{2}$ mole fraction. Four NOAA-calibrated tertiary standards (traceable to the WMO X2004 scale for $\mathrm{CH}_{4}$ and the WMO X2007 scale for $\mathrm{CO}_{2}$ ) were used for the linear mole fraction calibration, as described in Richardson et al. (2017). These NOAA tertiary standards ranged between 1790 and $2350 \mathrm{ppb} \mathrm{CH}_{4}$, and between 360 and $450 \mathrm{ppm} \mathrm{CO}_{2}$.

To calibrate the $\delta^{13} \mathrm{CH}_{4}$ measurement prior to deployment, four different target mixing ratios, each at four different known isotopic ratios, were tested by the four analyzers using the experimental setup in Fig. 3. Commercially available isotopic standard bottles (Isometric Instruments, Inc., product numbers L-iso1, B-iso1, T-iso1, and $\mathrm{H}$-iso1) were diluted with zero air to produce mixtures with varying $\mathrm{CH}_{4}$ mixing ratios and $\delta^{13} \mathrm{CH}_{4}$. The gravimetrically determined zero air (Scott Marrin, Inc.) was natural ultra-pure air, containing no methane or other alkanes but ambient levels of $\mathrm{CO}_{2}$. The isotopic calibration standard bottles each contained approximately $2500 \mathrm{ppm}$ of $\mathrm{CH}_{4}$ at $-23.9,-38.3$, -54.5 , and $-66.5 \% \circ \delta^{13} \mathrm{CH}_{4}$, with uncertainty of $\pm 0.2 \%$, reported by the supplier. These isotopic ratios were tied to 


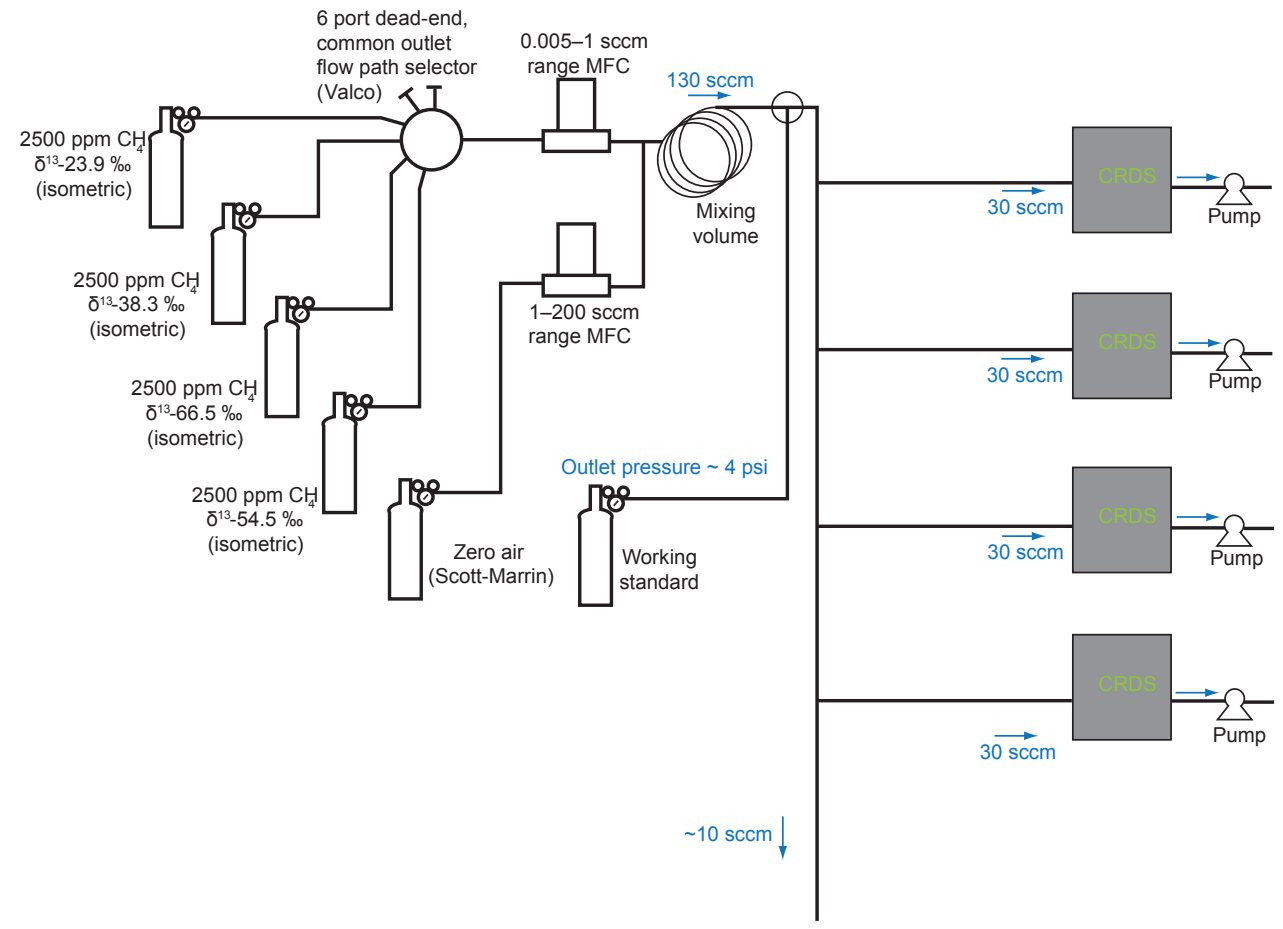

Figure 3. Flow diagram of the experimental setup used for the laboratory calibration of the analyzers and the field tanks (working standards). At standard pressure and temperature, the gas volume of the zero air and working standard tanks was $4021 \mathrm{~L}$, and that of the Isometric Instruments bottles was $28 \mathrm{~L}$.

the Vienna Pee Dee Belemnite (VPDB) scale. Mass flow controllers (MC-1SCCM and MC-500SCCM, Alicat Scientific, Inc.) and a six-port rotary valve (EUTA-2SD6MWE, Valco Instruments Co., Inc.) were used to direct the standard bottle air for each isotopic calibration standard bottle into a mixing volume $(\sim 4 \mathrm{~m}$ of $1 / 8$ in. $(0.32 \mathrm{~cm})$ OD stainless steel tubing; TSS285-120F, VICI Precision Sampling, Inc.) at $0.400 \mathrm{sccm}$ (standard cubic centimeter per minute) and mixed with zero $\mathrm{CH}_{4}$ air at $137,161,303$, and $555 \mathrm{sccm}$ to create target $\mathrm{CH}_{4}$ mole fractions of $7.3,6.2,3.3$, and $1.8 \mathrm{ppm}$, respectively. Thus $16 \mathrm{CH}_{4}$ mole fraction-isotopic ratio pairs were produced. The accuracy of the mass flow controllers can be a significant source of error in making mixtures. Here the nominal range of the mass flow controllers was $1 \mathrm{sccm}$ for the standard bottle line and $500 \mathrm{sccm}$ for the zero-air line, and the accuracy was $\pm 0.2 \%$ of full scale. To avoid isotopic fractionation at the head of the low-flow mass flow controller, the flow of the zero air was varied rather than the isotope standard. It is possible that fractionation did occur due to the tees used to direct gas into the individual analyzers. For this reason, it would have been preferable to set up the analyzers to each sample directly from the mixing volume.

The first mixture of each isotopic standard was tested for $60 \mathrm{~min}$ to flush out the span gas line and to avoid isotopic fractionation at the head of the span mass flow controller. Subsequent dilutions using the same isotopic standard were tested for $20 \mathrm{~min}$ each, and each dilution was repeated twice.

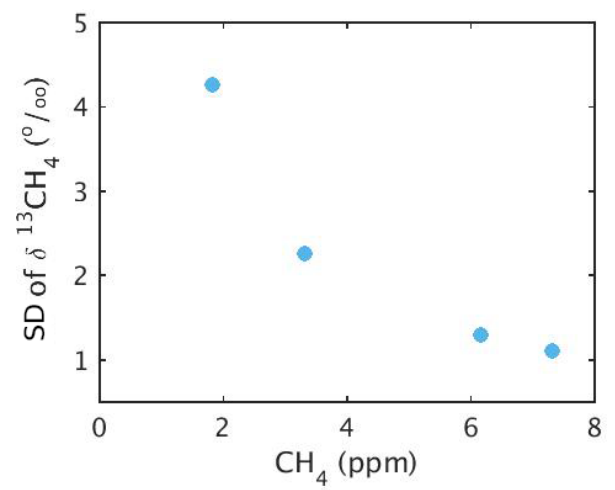

Figure 4. Standard deviation (SD) of the $\mathrm{CH}_{4}$ isotopic ratio during the test results shown in Fig. 5.

With the flow rate of $0.400 \mathrm{sccm}$ for the isotopic standard bottles, the total volume of standard gas used was $88 \mathrm{cc}$. Observations were collected at $\sim 0.5 \mathrm{~Hz}$, and the final $5 \mathrm{~min}$ of data for each dilution were averaged to compare against the target value. The standard deviation of the raw data collected during these tests (Fig. 4) decreases exponentially with increasing mole fraction.

Averaged methane isotopic ratios prior to calibration are shown in Fig. 5. There is an offset in the measured isotopic ratio as a function of the changing known isotopic ratio. For 
higher mole fractions, this offset is fairly constant, but for near-ambient mole fractions it is analyzer-specific. We note that the precision of these results could be improved by averaging over longer periods. We now describe the calibration technique to remove these offsets.

\subsection{Application of calibration equations}

The first step in the calibration process for the analyzers is to remove the nearly linear error that is a function of isotopic ratio. We applied methods leading from the theoretical framework developed by Rella et al. (2015) to calibrate the isotopic ratio data. Applying a linear fit to highest mole fraction values (7.3 ppm) measured in the laboratory for known $\delta^{13} \mathrm{CH}_{4}$ values $(-23.9,-38.3,-54.5,-66.5 \%$ o $)$ for each analyzer, we determined the linear calibration coefficients $p_{1}$ and $p_{0}$.

$\left[\delta^{13} \mathrm{CH}_{4}\right]_{\text {intermediate }}=p_{1}\left[\delta^{13} \mathrm{CH}_{4}\right]_{\text {measured }}+p_{0}$

For this step, we used only the highest mole fraction values because $\delta^{13} \mathrm{CH}_{4}$ is more precise for higher mole fractions (Fig. 4). We note that these laboratory tests were completed prior to the Allan standard deviation testing and that the averaging times were not sufficient to achieve the desired compatibility at ambient mole fractions. Ambient mole fractions could be used for this step if measured for sufficient durations.

To correct for the $\mathrm{CH}_{4}$ mole fraction dependence of the measured $\delta^{13} \mathrm{CH}_{4}$, the two time-dependent drift parameters described in Rella et al. (2015), $c_{0}$ and $\chi$, must be determined. Here $c_{0}$ varies because of spectral variations in the optical loss of the empty cavity, and $\chi$ varies because of errors in the temperature or pressure of the gas, or changes in the wavelength calibration. These parameters are defined in Eq. (15) of Rella et al. (2015). A coefficient describing the changes in the crosstalk between the two methane isotopologues was ignored, following Rella et al. (2015). For the laboratory calibration, we determined $c_{0}$ and $\chi$ using measurements at $-23.9 \%$ for a high mole fraction $(7.3 \mathrm{ppm})$ and a low mole fraction (1.8 ppm). We then applied Eq. (12) of Rella et al. (2015),

$$
\begin{aligned}
& {\left[\delta^{13} \mathrm{CH}_{4}\right]_{\text {calibrated }}=\left[\delta^{13} \mathrm{CH}_{4}\right]_{\text {intermediate }}} \\
& +\frac{c_{0}}{c_{12}}+\chi\left(\left[\delta \delta^{13} \mathrm{CH}_{4}\right]_{\text {intermediate }}-B\right),
\end{aligned}
$$

to correct for the $\mathrm{CH}_{4}$ mole fraction dependence of $\delta^{13} \mathrm{CH}_{4}$. Here $c_{12}$ is the measured $\left[{ }^{12} \mathrm{CH}_{4}\right]$, and

$$
B=p_{1} B_{\text {default }}+p_{0},
$$

with $B_{\text {default }}$ being $-1053.59 \%$. $B_{\text {default }}$ is the intercept of the fit of the isotopic ratio to the ratio of the absorption peak heights for the standard calibration, and $B$ is the updated value, specific to the analyzer. We followed Rella et al. (2015) and ignored the contribution of an additional offset term that depends on neither mole fraction nor isotopic ratio. Note that the slope of the linear calibration was the only component of the calibration that was not adjusted in the field using field tanks (Sect. 5.4).

\section{Methods: field deployment}

\subsection{In situ field tanks}

At each tower site, three field tanks were utilized, as listed in Table 1 . One tank at each tower site was calibrated by NOAA for $\mathrm{CH}_{4}$ and $\mathrm{CO}_{2}$ mole fractions and by the Institute of Arctic and Alpine Research (INSTAAR) for $\delta^{13} \mathrm{CH}_{4}$. This tank was tested quasi-daily (every $21 \mathrm{~h}$ ) and used to adjust the intercept for the $\mathrm{CH}_{4}$ and $\mathrm{CO}_{2}$ mole fraction calibrations (Richardson et al., 2017). The constituents of this tank were at typical ambient levels (as listed in Table 1); for the purposes of this paper, we call it the "target", although it was not independent.

Two additional tanks were tested at each of the tower sites (Table 1). Scott Marrin, Inc., filled these tanks using ultrapure air spiked with high methane air from Isometric Instruments, Inc., bottles. The resulting mixtures contained 1.9$2.1 \mathrm{ppm} \mathrm{CH}_{4}$ at $-23.9 \% \circ \delta^{13} \mathrm{CH}_{4}$ and 9.7-10.5 $\mathrm{ppm} \mathrm{CH}_{4}$ at $-38.3 \%$ o $\left.\delta^{13} \mathrm{CH}_{4}\right)$. Recall that these are called the "low" and "high" tanks, for simplicity. These tanks contained ambient levels of $\mathrm{CO}_{2}$ (368-407 ppm). The choice of the $\mathrm{CH}_{4}$ mole fraction of the high tank is based on the optimal determination of the calibration coefficients $c_{0}$ and $\chi$, rather than the expected range of ambient $\mathrm{CH}_{4}$ mole fractions. The effect of $c_{0}$ on the calibrated isotopic ratio is largest at low mole fractions, whereas the effect of $\chi$ is independent of mole fraction. Thus the ratio of the high- and low-tank mole fractions determines how separable the two effects are. We therefore chose the high-tank mole fraction to be as high as possible without introducing other nonlinearities into the system.

The high and low tanks for each tower were calibrated for $\delta^{13} \mathrm{CH}_{4}$ in the laboratory prior to deployment. First we applied a linear calibration for $\delta^{13} \mathrm{CH}_{4}$ using measurements from each of four Isometric Instruments bottles $(-23.9$, $-38.3,-54.5,-66.5 \%$ ) , diluted with zero air to $10.3-$ $10.4 \mathrm{ppm} \mathrm{CH}_{4}$. A three-way solenoid valve (091-0094-900, Parker Hannifin Corp.) was used just downstream of the mixing volume in the laboratory calibration system to stop flow from the zero-air tank and Isometric Instrument bottles and to allow flow from the working standards. Then a mole fraction correction was applied using the $-23.9 \%$ bottle diluted to $10.4 \mathrm{ppm} \mathrm{CH}_{4}$ and the $-38.3 \%$ o bottle diluted to $1.9 \mathrm{ppm}$. These calibration results are shown in Table 1. The values assigned to the tanks differed slightly (with the differences ranging in magnitude from 0.01 to $0.38 \%$ ) from the bottles used for spiking. Possible reasons for these slight differences include noise in the measurement, fractionation upon tank filling, bottle assignment error with the $0.2 \%$ uncertainty re- 

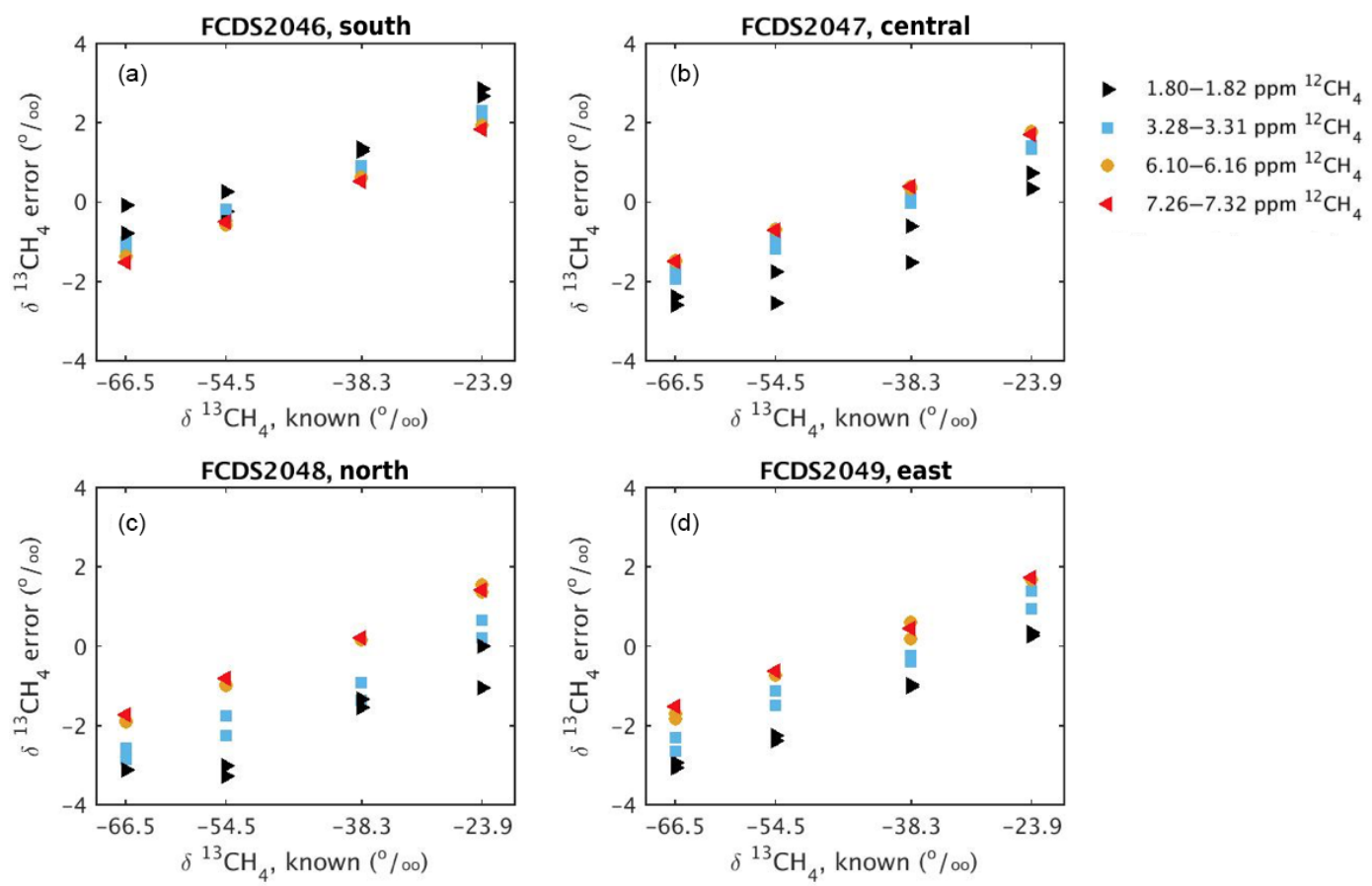

Figure 5. Measured isotopic ratio error as a function of known isotopic ratio for each of the four analyzers (a-d), prior to calibration. The colors indicate the ${ }^{12} \mathrm{CH}_{4}$ mole fraction, as shown in the legend. The serial numbers (FCDS2046, FCDS2047, FCDS2048, and FCDS2049) of the analyzers are indicated as well. These analyzers were deployed at the south, central, north, and east towers, respectively. Interpolating

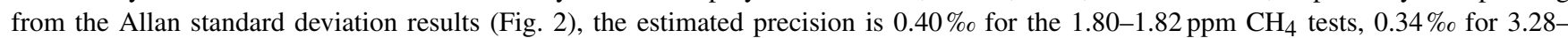
$3.32 \mathrm{ppm} \mathrm{CH}_{4}$ tests, $0.24 \%$ or $6.10-6.16 \mathrm{ppm} \mathrm{CH}_{4}$ tests, and $0.20 \%$ or $7.26-7.32 \mathrm{ppm}^{\mathrm{CH}_{4}}$ tests.

ported by the supplier (Isometric Instruments, Inc.), and insufficient testing times for the tanks at ambient mole fractions ( $5 \mathrm{~min}$ ). We note that it would have been preferable to utilize calibration tanks closer to the observed air samples in terms of isotopic ratio. In particular, the low tank could have been spiked with the $-38.3 \%$ o bottle, or a mixture of the -38.3 and $-54.5 \%$ bottles.

\subsection{In situ field calibration gas sampling system}

The flow diagram of the field calibration system is shown in Fig. 6. Polyethylene/aluminum composite tubing (1/4 in. $(0.64 \mathrm{~cm})$ OD, Synflex 1300, Eaton Corp.) was used to sample from the top of each tower for the CRDS analyzer, and a separate sample line made from $3 / 8$ in $(0.95 \mathrm{~cm})$ OD Synflex 1300 tubing was used for the flask sampling packages. The top end of each tube was equipped with a rain shield to prevent liquid water from entering the sampling line. For the CRDS analyzer, air was drawn down the tube at $1 \mathrm{~L} \mathrm{~min}^{-1}$, with $30 \mathrm{cc} \mathrm{min}^{-1}$ flow into the analyzer, and the remainder purged. The residence time in the tube was about $1 \mathrm{~min}$. Separate tubes were used for the CRDS and flask sampling lines because of the differing flow rates required for the flask samples (varying between 0.29 and $3.8 \mathrm{~L} \mathrm{~min}^{-1}$; Turnbull et al., 2012) and to ensure independence of the CRDS and flask measurements.
For the continuous in situ measurement system, switching between sample and calibration gases was accomplished using a six-port rotary valve (EUTA-2SD6MWE, Valco Instruments Co, Inc.). Stainless steel tubing $(1 / 8 \mathrm{in} .(0.32 \mathrm{~cm}) \mathrm{OD}$, TSS285-120F, VICI Precision Sampling, Inc.) and singlestage regulators (Y11-C444B590, Airgas, Inc.) were used for testing the field tanks. Rella et al. (2015) noted that the effect of water vapor on the isotopic ratio of methane measurement is up to $1 \%$ and nonlinear, and recommended drying to less than $0.1 \% \mathrm{H}_{2} \mathrm{O}$ mole fraction. Thus we used a Nafion dryer (MD-070-96S-2, PermaPure) in the reflux configuration, with an additional pump (ME1, Vacuubrand, Inc.) on the outlet of the Nafion dryer (Fig. 6). The sample air was dried to $\sim 0.06 \% \mathrm{H}_{2} \mathrm{O}$, and the calibration gases were humidified to $0.02 \% \mathrm{H}_{2} \mathrm{O}$, in a manner similar to Andrews et al. (2014). The $\mathrm{CH}_{4}$ mole fraction was corrected for water vapor following Rella et al. (2015, Supplement), and the $\mathrm{CO}_{2}$ mole fraction following Chen et al. (2010).

A cycle including $90 \mathrm{~min}$ of ambient sampling, 6 min testing the high mole fraction field tank, and 10 min testing the low mole fraction field tank was repeated $12 \times$; then the target tank was tested for $10 \mathrm{~min}$ (occurring every $\sim 21 \mathrm{~h}$, to test for diurnal effects). Thus, there were 13.5 calibration cycles for the high and low tanks each day, on average. The first 4 min of data were discarded each time after switching gases to ensure sufficient flushing of the sample cell. After 
Table 1. Field tanks used at the tower locations. The high and target tanks were used for the field calibration of $\delta^{13} \mathrm{CH}_{4}$. Only the target tank is used for field adjustment of the $\mathrm{CH}_{4}$ and $\mathrm{CO}_{2}$ mole fraction calibration. The $\mathrm{CH}_{4}$ and $\mathrm{CO}_{2}$ mole fractions for the high and low tanks are less certain than those of the target tanks.

\begin{tabular}{|c|c|c|c|c|c|c|c|c|}
\hline $\begin{array}{l}\text { Tank } \\
\text { number }\end{array}$ & $\begin{array}{l}\text { Deployment } \\
\text { location }\end{array}$ & $\begin{array}{r}\text { Measured } \\
\text { isotopic } \\
\text { ratio } \\
\delta^{13} \mathrm{CH}_{4} \\
(\% \text { o })\end{array}$ & $\begin{array}{r}\mathrm{CH}_{4} \text { mole } \\
\text { fraction } \\
(\mathrm{ppb})\end{array}$ & $\begin{array}{r}\mathrm{CO}_{2} \text { mole } \\
\text { fraction } \\
(\mathrm{ppm})\end{array}$ & $\begin{array}{r}\text { Used for } \\
\text { field } \\
\text { calibration } \\
\text { of } \delta^{13} \mathrm{CH}_{4}\end{array}$ & $\begin{array}{r}\text { Independent } \\
\text { test of } \\
\delta^{13} \mathrm{CH}_{4} \\
\text { calibration }\end{array}$ & $\begin{array}{r}\text { Used for } \\
\text { field } \\
\text { adjustment } \\
\text { of } \mathrm{CH}_{4} \text { and } \\
\mathrm{CO}_{2} \text { mole } \\
\text { fraction } \\
\text { calibration } \\
\text { (intercept } \\
\text { only) }\end{array}$ & $\begin{array}{r}\text { Used for } \\
\text { ethane } \\
\text { correction }\end{array}$ \\
\hline CA06418 & North-high & $-38.31^{\mathrm{a}}$ & $9701^{\mathrm{a}}$ & $397.75^{c}$ & $\checkmark$ & & & $\checkmark$ \\
\hline CA05551 & North-low & $-23.67^{\mathrm{a}}$ & $1926.8^{a}$ & $402.70^{\mathrm{c}}$ & & $\checkmark$ & & \\
\hline CB10825 & North-target & $-47.26^{\mathrm{b}}$ & $1867.59^{\mathrm{b}}$ & $399.71^{b}$ & $\checkmark$ & & $\checkmark$ & $\checkmark$ \\
\hline CA05419 & Central-high & $-38.48^{\mathrm{a}}$ & $10534^{\mathrm{a}}$ & $399.66^{c}$ & $\checkmark$ & & & $\checkmark$ \\
\hline CA06438 & Central-low & $-23.80^{\mathrm{a}}$ & $2064.6^{\mathrm{a}}$ & $397.82^{c}$ & & $\checkmark$ & & \\
\hline CB10734 & Central-target & $-47.25^{\mathrm{b}}$ & $1878.53^{b}$ & $397.09^{b}$ & $\checkmark$ & & $\checkmark$ & $\checkmark$ \\
\hline CA05330 & South-high & $-38.68^{\mathrm{a}}$ & $10152^{\mathrm{a}}$ & $403.10^{\mathrm{c}}$ & $\checkmark$ & & & $\checkmark$ \\
\hline CC114999 & South-low & $-23.72^{\mathrm{a}}$ & $1999.2^{\mathrm{a}}$ & $402.58^{\mathrm{c}}$ & & $\checkmark$ & & \\
\hline CB10727 & South-target & $-47.24^{b}$ & $1868.33^{b}$ & $399.68^{b}$ & $\checkmark$ & & $\checkmark$ & $\checkmark$ \\
\hline CA06410 & East-high & $-38.52^{\mathrm{a}}$ & $10414^{\mathrm{a}}$ & $407.45^{\mathrm{c}}$ & $\checkmark$ & & & $\checkmark$ \\
\hline CA06357 & East-low & $-24.02^{\mathrm{a}}$ & $2079.7^{\mathrm{a}}$ & $368.47^{\mathrm{c}}$ & & $\checkmark$ & & \\
\hline CB10718 & East-target & $-47.26^{b}$ & $1867.94^{\mathrm{b}}$ & $399.67^{b}$ & $\checkmark$ & & $\checkmark$ & $\checkmark$ \\
\hline
\end{tabular}

${ }^{a}$ Determined via laboratory measurements. ${ }^{\mathrm{b}}$ NOAA/INSTAAR calibration (WMO X2004A scale for $\mathrm{CH}_{4}$ and WMO X2007 for $\mathrm{CO}_{2}$ ). ${ }^{\mathrm{c}}$ Field calibration - values not used.

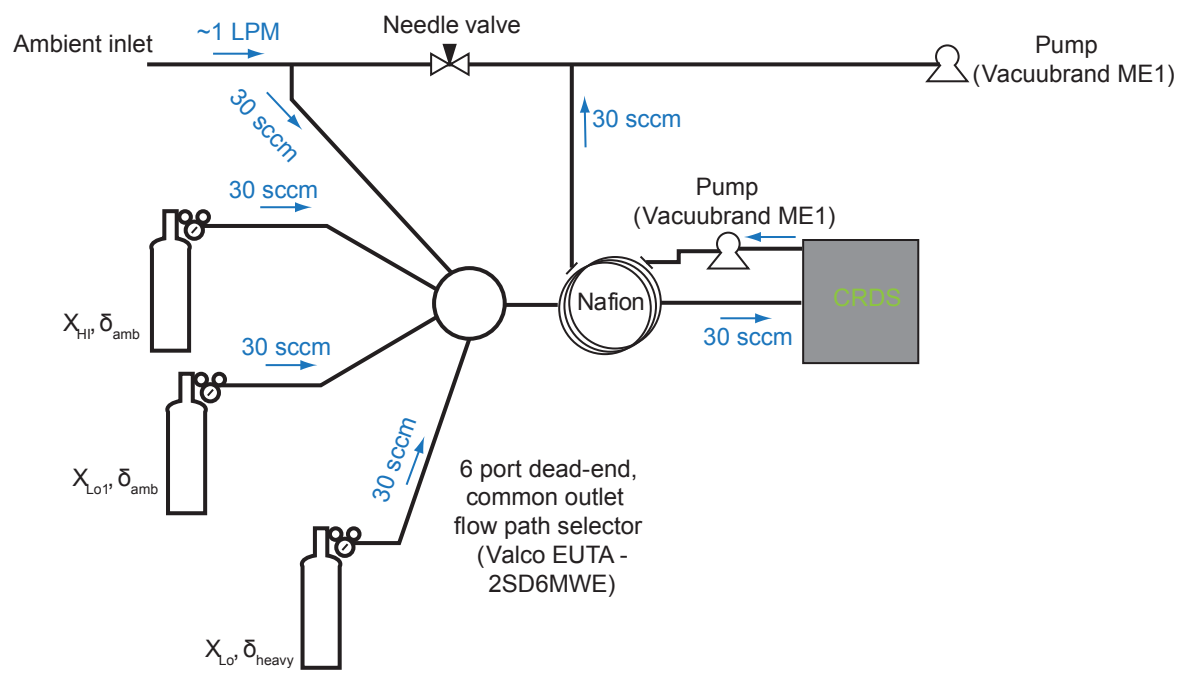

Figure 6. Flow diagram of the field calibration system. At standard pressure and temperature, the gas volume of the field tanks was $4021 \mathrm{~L}$.

this time, the $\mathrm{CO}_{2}$ and $\mathrm{CH}_{4}$ mole fractions stabilized. The ideal calibration tank testing time is a balance between minimizing calibration gas usage (and consequently maximizing ambient air sampling time) and achieving sufficient precision. Note that the Allan standard deviation results indicate that testing for $4 \mathrm{~min}$ for the high tank and for $32 \mathrm{~min}$ for the low and target tanks is required to achieve our target com- patibility of $0.2 \% \circ \delta^{13} \mathrm{CH}_{4}$. Thus, this averaging time was achieved in two calibration cycles for the high tank (excluding flushing time), but in 5.3 calibration cycles for the low and target tanks (completed in about $10 \mathrm{~h}$ in the case of the sampling scheme utilized for most of the deployment). An improved sampling strategy was implemented on 3 December 2016 and is discussed in Sect. 5.4. 
The flow rate of the instruments was $35 \mathrm{cc} \mathrm{min}^{-1}$, and the $150 \mathrm{~A}$ tank size was used, corresponding to $4.021 \times 10^{6} \mathrm{cc}$ at standard pressure and temperature. Thus there was sufficient gas to test each tank for about $1 \mathrm{~h}$ per day for about 5 years, as a general guideline.

\subsection{Cross-interference from other species}

\subsubsection{Overview}

The effects of cross-interference from other species must be considered for spectroscopic measurements. Rella et al. (2015) give proportional relationships for crossinterference from various species for the G2132-i analyzers. Listed in Table 2 are species with potential to affect the isotopic methane calibration and their estimated effects for tower-based applications. We based these estimates on typical maximum values determined by flask (level at which $99 \%$ of flask measurements at the south and east towers were below; for carbon monoxide, propane, butane, ethylene, and ethane), by in situ measurements at the towers in this deployment (for water vapor and carbon dioxide), and by typical values (Warneck and Williams, 2012; for ammonia and hydrogen sulfide). There are no known ambient estimates for methyl mercaptan (Barnes, 2015), so the odor threshold (Devos et al., 1990) was used as a maximum value.

For the Picarro G-2132i analyzers, ethane contributed the largest interference, and a correction to the isotopic ratio was applied (Sect. 4.4.2). Because of water vapor effects, the sample was dried, and the calibration gases were humidified. The effects of other species were neglected.

\subsubsection{Ethane correction}

Ethane $\left(\mathrm{C}_{2} \mathrm{H}_{6}\right)$ is co-emitted with methane during natural gas extraction, and its cross-interference with the isotopic ratio of methane is significant. The magnitude of the effect of ethane on the isotopic methane is proportional to its mole fraction and inversely proportional to the methane mole fraction. The two Scott Marrin field tanks at each site were scrubbed of alkanes (including ethane), but the one NOAA/INSTAAR field tank at each site contained ambient levels of these species. Typical mole fractions of $\mathrm{C}_{2} \mathrm{H}_{6}(1.3 \mathrm{ppb})$ compared to the Scott Marrin tanks containing no ethane would lead to a $0.04 \%$ bias if uncorrected. Furthermore, flask measurements at the south and east towers indicated ethane up to $8 \mathrm{ppb}$, which corresponds to a $0.23 \%$ o error.

The G2132-i analyzers reported an ethane measurement but were not designed for high-compatibility $\mathrm{C}_{2} \mathrm{H}_{6}$ measurements at levels near background. In this deployment, $99 \%$ of the flask measurements, which were taken in the afternoon, were less than $8.0 \mathrm{ppb}_{2} \mathrm{H}_{6}$. In comparison, the drives near natural gas sources conducted by Rella et al. (2015) indicated $\mathrm{C}_{2} \mathrm{H}_{6}$ mole fractions up to $13 \mathrm{ppm}$ (note unit change). The ethane signal is subject to strong cross-interference from wa- ter vapor, methane, and carbon dioxide. Rella et al. (2015; Eq. S20) report coefficients for these corrections. These coefficients indicate corrections larger in magnitude than the ethane mole fractions measured in this deployment. We have thus not attempted to analyze the ethane results themselves. The ethane output was, however, used to correct the isotopic methane data. To do so, we first developed a linear calibration using the Scott Marrin high field tank containing zero ethane and the NOAA/INSTAAR target tank which we assumed contained a background level of $1.5 \mathrm{ppb}$ ethane (Peischl et al., 2016). This calibration is clearly a rough estimate. Note that we determined the linear relationship between the reported ethane of each analyzer and its calibrated value initially, and assumed that this relationship does not change throughout the deployment. Newer models of the $\delta^{13} \mathrm{CH}_{4}$ analyzer (G2210-i, Picarro, Inc.) measure $\mathrm{C}_{2} \mathrm{H}_{6}$ at ppb levels, simplifying this correction process.

We then corrected the isotopic methane for the effects of ethane cross-interference. For example, $1.3 \mathrm{ppb}$ of ethane in an air sample of $2 \mathrm{ppm} \mathrm{CH}_{4}$ would, if uncorrected, shift the $\delta^{13} \mathrm{CH}_{4}$ measurement higher by $[+58.56 \%$ opm $\mathrm{CH}_{4}\left(\mathrm{ppm} \mathrm{C}_{2} \mathrm{H}_{6}\right)^{-1} \times\left[0.0013 \mathrm{ppm} \mathrm{C}_{2} \mathrm{H}_{6}\right] /\left[2 \mathrm{ppm} \mathrm{CH} \mathrm{CH}_{4}\right]=$ $+0.04 \%$. Note that the calibration coefficient for ethane has been updated from that indicated in Rella et al. (2015). The correction to compensate for this error was applied to all data, using the estimated ethane and measured methane values.

\subsubsection{Water vapor and carbon dioxide}

Water vapor can have a significant effect on the measurements of isotopic methane (up to $\pm 1 \%$ o for up to $2.5 \% \mathrm{H}_{2} \mathrm{O}$; Rella et al., 2015). Thus, the sample air was dried and the calibration gases were slightly humidified such that this effect is minimized (estimated to be $<0.02 \%$ ). For the range of ambient $\mathrm{CO}_{2}$ observed in this study $(\sim 375-475 \mathrm{ppm})$, the difference from the calibration gases was $\sim 100 \mathrm{ppm}$, and the effect was estimated to be $<0.03 \%$ o (Table 2). The isotopic ratio of methane was thus not corrected for $\mathrm{CO}_{2}$ effects.

\subsubsection{Oxygen, argon, and carbon monoxide}

The ambient variability in oxygen, argon, and carbon monoxide is expected to have a negligible effect on the isotopic ratio measurements (Rella et al., 2015), and no corrections for these constituents were applied to the isotopic methane data.

\subsubsection{Other species}

Ammonia, hydrogen sulfide, methyl mercaptan, propane, butane, and ethylene are components of natural gas, but their cross-interference effects were small for our tower-based application for which the sources are relatively far from the measurement location. The effects of these species may be significant for other applications, such as automobile-based measurements. Like for ethane, the magnitude of the effect 
Table 2. Maximum error estimate attributable to cross-interference due to direct absorption on $\delta^{13} \mathrm{CH}_{4}$. These estimates were based on typical values for this tower-based application and estimated effects on CRDS measurements (Rella et al., 2015), and assumed 2 ppm ambient $\mathrm{CH}_{4}$ mole fraction. For water vapor and carbon dioxide, the interferences are independent of $\mathrm{CH}_{4}$ mole fraction for 1-15 ppm. For the other species listed, the interferences are inversely proportional to $\mathrm{CH}_{4}$ mole fraction. Typical maximum values determined by flask ${ }^{\mathrm{f}}$ (level at which $99 \%$ of (afternoon) flask measurements at the south and east towers are below), by in situ measurements at Marcellus towersi ${ }^{\mathrm{i}}$, or by typical values ${ }^{\mathrm{t}}$ (Warneck and Williams, 2012).

\begin{tabular}{|c|c|c|}
\hline Gas species & Typical maximum value or range & Estimated maximum error \\
\hline Carbon monoxide & Range $^{\text {f: }}: 107.5-200.7 \mathrm{ppb}$ & $0.01 \%$ \\
\hline Water vapor, dried sample & Range $^{\mathrm{i}}: 0.02-0.06 \%$ & $0.02 \%$ \\
\hline Water vapor, ambient moisture & Range: $0-2.5 \%$ & $\pm 1 \%$ (Rella et al., 2015) \\
\hline Carbon dioxide & Range $^{\mathrm{i}}: 375-475 \mathrm{ppm}$ & $0.03 \%$ \\
\hline Propane & $\operatorname{Max}^{\mathrm{f}} 3.6 \mathrm{ppb}$ & $0.01 \% \circ$ \\
\hline Butane ( $i$-butane $+n$-butane) & $\operatorname{Max}^{\mathrm{f}} 1788 \mathrm{ppt}$ & $0.01 \% \circ$ \\
\hline Ammonia & Typical $^{\mathrm{t}} 90 \mathrm{ppt}$ & $0.01 \%$ \\
\hline Hydrogen sulfide & Typical $^{\mathrm{t}} 30 \mathrm{ppt}$ & $0.01 \% 0$ \\
\hline Methyl mercaptan & Odor threshold*: $1 \mathrm{ppb}$ & $0.01 \% \circ$ \\
\hline Ethylene & $13.0^{\mathrm{f}} \mathrm{ppt}$ & $0.01 \%$ \\
\hline Ethane & $\operatorname{Max}^{\mathrm{f}} 8.0 \mathrm{ppb}$ (typical background ${ }^{t}: 1.3 \mathrm{ppb}$ ) & $0.23 \%$ (0.04\% typical) \\
\hline
\end{tabular}

* No known ambient estimates (Barnes, 2015)/odor threshold (Devos et al., 1990).

Table 3. Results for the four Marcellus towers using two possible calibration schemes. Tank errors are shown for using the high and low tank in the calibration (scheme A) and using the high and target tank in the calibration (scheme B). The third set of results are for scheme B, but following the change in field tank testing times on 3 December 2016. Results are from October 2016 for the south, east, and north towers but are from May 2016 for the central tower, as the analyzer was at the manufacturer for repairs during October 2016. Note that the daily means of the field tanks are used in the calibrations.

\begin{tabular}{lllll}
\hline & Tower & $\begin{array}{l}\text { High-tank error (\%o) } \\
\text { mean } \pm \text { standard } \\
\text { deviation for one month } \\
\text { (standard error) }\end{array}$ & $\begin{array}{l}\text { Low-tank error (\%o) } \\
\text { mean } \pm \text { standard } \\
\text { deviation for one month } \\
\text { (standard error) }\end{array}$ & $\begin{array}{l}\text { Target-tank error (\%o) } \\
\text { mean } \pm \text { standard } \\
\text { deviation for one month } \\
\text { (standard error) }\end{array}$ \\
\hline Scheme A & South & Used in cal & Used in cal & $-0.3 \pm 0.4(0.1)$ \\
Scheme A & East & Used in cal & Used in cal & $-0.8 \pm 0.5(0.1)$ \\
Scheme A & Central & Used in cal & Used in cal & $-0.5 \pm 0.3(0.1)$ \\
Scheme A & North & Used in cal & Used in cal & $-0.4 \pm 0.7(0.1)$ \\
Scheme B & South & Used in cal & $0.2 \pm 0.7(0.0)$ & Used in cal \\
Scheme B & East & Used in cal & $0.7 \pm 0.6(0.0)$ & Used in cal \\
Scheme B & Central & Used in cal & $0.4 \pm 0.5(0.0)$ & Used in cal \\
Scheme B & North & Used in cal & $0.3 \pm 1.3(0.1)$ & Used in cal \\
Scheme B* & South & Used in cal & $0.3 \pm 0.3(0.0)$ & Used in cal \\
Scheme B* & East & Used in cal & $0.6 \pm 0.5(0.0)$ & Used in cal \\
Scheme B* & Central & Used in cal & $0.4 \pm 0.3(0.0)$ & Used in cal \\
Scheme B* & North & Used in cal & $-0.4 \pm 0.9(0.0)$ & Used in cal \\
\hline
\end{tabular}

* Following change in field tank testing times on 3 December 2016.

of these gases on the isotopic methane is proportional to the mole fraction of the contaminant species and inversely proportional to the methane mole fraction. In Table 2, maximum mole fractions from the flasks if available, or typical mole fractions from the literature, were used to estimate the effect of these species for our application. The crossinterference from these species was insignificant for our application, $<0.01 \%$.

\subsection{Field calibration}

The linear calibration was determined in the laboratory as described in Sect. 4.2. We then used the daily average of the high and target field tanks to adjust the mole fraction correction (terms $c_{0}$ and $\chi$ ) for the field data. The low tank was used as an independent test. For October 2016, the mean errors for the low tank at the south tower are $0.2 \pm 0.7 \%$, for example (Table 3, scheme B). Here the standard deviation 

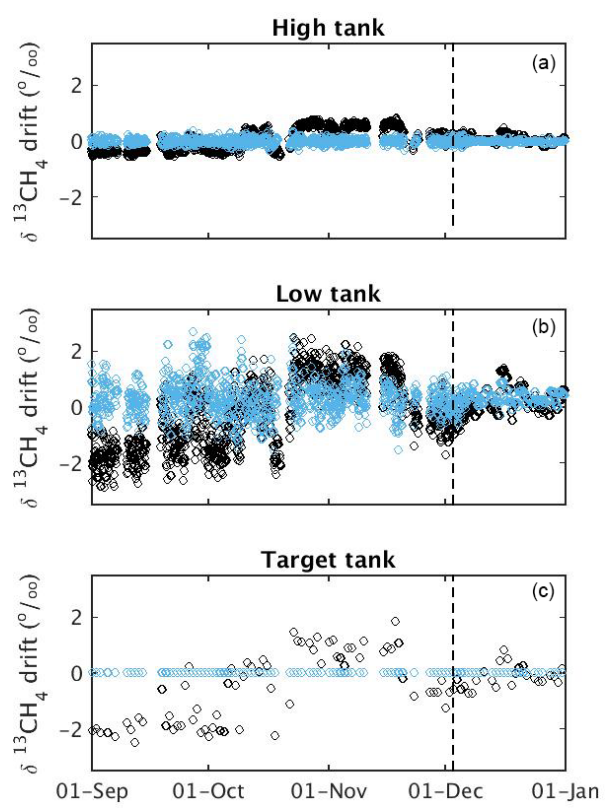

Figure 7. Results following isotopic ratio laboratory calibration only (black) and following calibration (blue) for the south tower for September-December 2016 for the "high" $\mathrm{CH}_{4}$ mole fraction tank (a), "low" $\mathrm{CH}_{4}$ mole fraction tank (b), and target tank (c). The target tank was used in the isotopic ratio calibration, whereas the low tank was independent. An improved calibration tank sampling strategy was implemented on 3 December 2016 (indicated by vertical dashed lines). The Allan deviation for the time period used for each calibration cycle was, for the period prior to the improved tank sampling strategy, $0.2 \%$ for the high tank and $0.5 \%$ or the low and target tanks. Following the implementation of the improved tank sampling strategy, the Allan deviation for each calibration cycle was $0.1 \%$ o for the high tank and $0.3 \%$ o for the low and target tanks.

was calculated using all of the calibration cycles during the month. The errors near the isotopic ratio of the target tank are likely less in magnitude. Instead using the low tank in the calibration and keeping the target tank independent yielded similar magnitudes of errors (Table 3, scheme A) but minimized bias near the low tank (about $-23.9 \%$ ) rather than near the target tank (about $-47.2 \%$ ). Therefore, despite increased testing of the low tank throughout the majority of the deployment, we chose to use the target tank in the calibration to minimize errors near-ambient isotopic ratios.

On 3 December 2016, an improved tank testing strategy was implemented, in which the target tank testing time

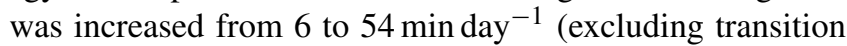
times), achieved by sampling for 20 min every 420 min cycle (3.4 times day ${ }^{-1}$, on average). The calibration times were completed using multiple cycles in order to avoid not sampling the atmosphere for long periods and to measure possible changes in analyzer response throughout each day. The low tank was tested using an identical strategy (20 min every 420 min cycle), with the total amount of testing time per
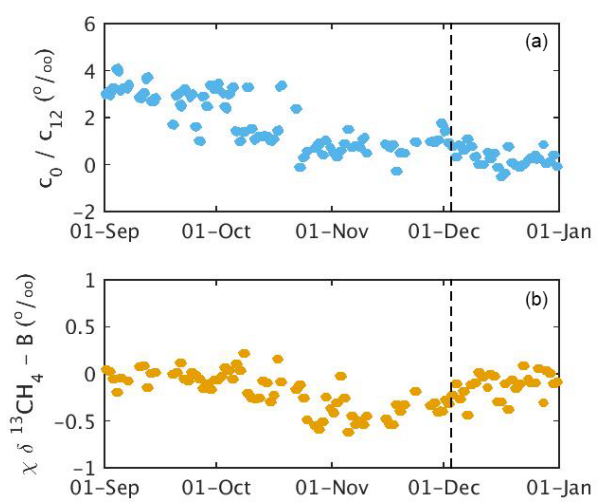

Figure 8. Effect of each of the calibration coefficient terms for the south tower for September-December 2016 for the optimized calibration scheme. The terms $c_{0}$ (a) and $\chi$ (b) in Eq. (3) are timedependent drift terms. Note the differing scales. An improved calibration tank sampling strategy was implemented on 3 December 2016 (indicated by vertical dashed lines).

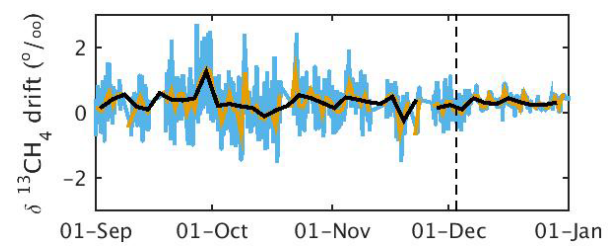

Figure 9. Low-tank methane isotopic ratio differences from known value, for the individual calibration cycles (blue), and for 1-day (red) and 3-day (black) means of the calibration cycles, for the south tower for September-December 2016. An improved calibration tank sampling strategy was implemented on 3 December 2016 (indicated by the vertical dashed line). The low tank is independent of the isotopic ratio calibration.

day changing from 81 to $54 \mathrm{~min}$. The high tank was tested on average $1.7 \times$ per day (every $840 \mathrm{~min}$ ) for $10 \mathrm{~min}$. Excluding the transition times, the high tank testing time was thus reduced from 26 to about $10 \mathrm{minday}^{-1}$. Following the implementation of the improved strategy, the mean error of the independent low tank at the sites was similar, but the standard deviation was reduced from 0.5 to 1.3 to 0.3 to $0.9 \%$ o (Table 3).

As an example of the effects of calibration, the tank results (differences from known values) using only the laboratory calibration for isotopic ratio and following scheme B are shown in Fig. 7 for the period September-December 2016. For the results using only the laboratory calibration, analyzer drift is apparent for all three tanks. Without a field calibration, the isotopic ratio was biased by up to $2 \%$. The target tank measurement was used in the calibration; hence the apparent drift following final calibration was necessarily zero. The noise apparent in Fig. $7 \mathrm{~b}$ prior to 3 December 2016, when the calibration scheme was improved, is at least partially due to insufficient sampling times of the target tank. 
The relative effects of the calibration terms are illustrated in Fig. 8. The terms $c_{0}$ (Fig. 8a) and $\chi$ (Fig. 8b) in Eq. (3) are time-dependent drift terms. These terms vary because of spectral variations in the optical loss of the empty cavity $\left(c_{0}\right)$ and because of errors in the temperature or pressure of the gas, or changes in the wavelength calibration $(\chi)$. Recall that the parameters $c_{0}$ and $\chi$ were calculated following Eq. (15) in Rella et al. (2015). The calculation of the parameter $c_{0}$ used measurements from the high and target tank. The calculation of the parameter $\chi$ used measurements of the high tank and was not independent from $p_{0}$. The largest calibration effect was from the $c_{0}$ term, which increased the calibrated isotopic ratios by -0.5 to $4 \%$ during September to December 2016 . The $\chi$ term increased the final calibrated isotopic ratios by a smaller amount, -0.6 to $0.2 \%$. Thus over this period, there were large changes in the calibration effect of these terms, although no software or hardware changes were applied. Considering shorter-term changes, the day-to-day changes in the calibration were less than $0.5 \%$ o for December 2016. Less frequent calibrations, e.g., twice per week, could be considered, but the reduction in field tank use is not large considering the low flow rates of the instruments and steady changes up to $2 \%$ in the raw data over the timescale of days were observed in Rella et al. (2015).

\section{Evaluation of the compatibility of in situ tower measurements}

\subsection{Independent low tank}

The low tank was treated as an ambient sample, independent of the calibration. To evaluate the noise in the calibrated ambient samples that results from noise in the calibration, we calculated the standard deviation over the period 1 September-2 December of the individual low-tank calibration cycles ( 6 min each), of the calibration cycles averaged over 1 day ( $81 \mathrm{~min}$ total), and of the calibration cycles averaged over 3 days $(4.1 \mathrm{~h}$ total). These results are a proxy for the noise in the calibrated ambient samples over those testing periods.

The low-tank differences from known values, averaged over differing intervals, are shown in Fig. 9. The standard deviation of individual low-tank calibration cycles (6 min each) over the period 1 September-2 December is $0.62 \%$. During this period, the calibration used 6 min day $^{-1}$ measurements of the target tank. The standard deviation of the low-tank calibration cycles was similar to expectations based on the Allan standard deviation (Fig. 2). The low tank was tested a total of $81 \mathrm{~min}(1.35 \mathrm{~h})$ per day. Thus calculating the standard deviation of the low-tank values averaged over each day is a measure of the noise due to the calibration scheme for hourly averages of sample data. The standard deviation of daily averages for the low tank (81 min total) was $0.40 \%$. Based on this result, differences in the hourly average be- tween towers of less than $0.40 \%$ were likely not significant. For 3-day means (a total of $4.1 \mathrm{~h}$ ), the standard deviation over the 3 -month period was $0.26 \%$. For the period after the calibration tank sampling scheme was improved (primarily by sampling the target tank for 54 min day $^{-1}$ instead of 6 min day $^{-1}$ ), 3-31 December, the standard deviation of the individual cycles reduced substantially, to $0.25 \%$, and that of the $81 \mathrm{~min}(4.1 \mathrm{~h})$ mean of the cycles was $0.18 \%$ o $(0.11 \%$ ). Therefore, according to this metric, after the improved calibration scheme was implemented, differences in the hourly average between towers of greater than $0.18 \%$ owere significant.

\subsection{Round-robin testing}

Post-deployment round-robin style tests were completed in the laboratory in March 2017 for three of the analyzers, to assess the compatibility achievable via our calibration method. The analyzer deployed at the south tower was not included in these tests, as it was still in the field. Two NOAA/INSTAAR tanks (JB03428: -46.82\%o $\delta^{13} \mathrm{CH}_{4}$, $1895.3 \mathrm{ppb} \mathrm{CH}_{4}$, and $381.63 \mathrm{ppm} \mathrm{CO}_{2} ; \mathrm{JB} 03412$ : $-45.29 \%$ ${ }^{13} \mathrm{CH}_{4}$, 2385.2 ppb $\mathrm{CH}_{4}$, and $432.71 \mathrm{ppm} \mathrm{CO}_{2}$ ) were tested and treated as unknowns. The uncertainty for these NOAA tertiary standards was $0.1 \mathrm{ppm} \mathrm{CO}_{2}$, including scale transfer (Hall, 2017; Zhao and Tans, 2006), and 1 ppb $\mathrm{CH}_{4}$ (GAW Report No. 185, 2009). The reproducibil-

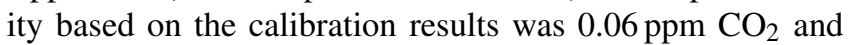
$0.4 \mathrm{ppb} \mathrm{CH}_{4}$. The isotopic ratio was tied to the VPDB scale but was not an official calibration (S. E. Michel and B. V. Vaughn, personal communication, 2015). The precision of the determined values assigned to the tanks was $0.04 \%$ (https://instaar.colorado.edu/research/labs-groups/ stable-isotope-laboratory/services-detail/). High, low, and target tanks were tested, with the calibration applied as in the field for ambient samples (as described in Sect. 5.4). The high mole fraction tank was tested for $20 \mathrm{~min}$, and the all ambient mole fraction tanks were tested for $70 \mathrm{~min}$, with 8 min ignored after each gas transition. Four to six tests were completed for each analyzer. We used these tests as a means of evaluating the compatibility of the analyzers, in terms of both mole fractions and the isotopic ratio.

The results for the round-robin style laboratory testing are shown in Fig. 10. The mean of the errors (measured NOAA known value) for each analyzer-tank pair was -0.08 to $0.04 \mathrm{ppm} \mathrm{CO}_{2}$, within the $0.1 \mathrm{ppm}$ WMO compatibility recommendation for global studies of $\mathrm{CO}_{2}$ (GAW Report No. 229, 2016). The standard error, indicating an estimate of how far the sample mean is likely to be from the true mean, for the means of the $\mathrm{CO}_{2}$ tests was $0.03-0.10 \mathrm{ppm}$. The mean difference was -0.03 to $0.02 \mathrm{ppm} \mathrm{CO}_{2}$ for the analyzers, averaged over the two round-robin tanks (analogous to averaging over the entire range of $\mathrm{CO}_{2}$ during the flask comparison, for example). For $\mathrm{CH}_{4}$, the means of the

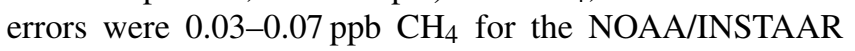



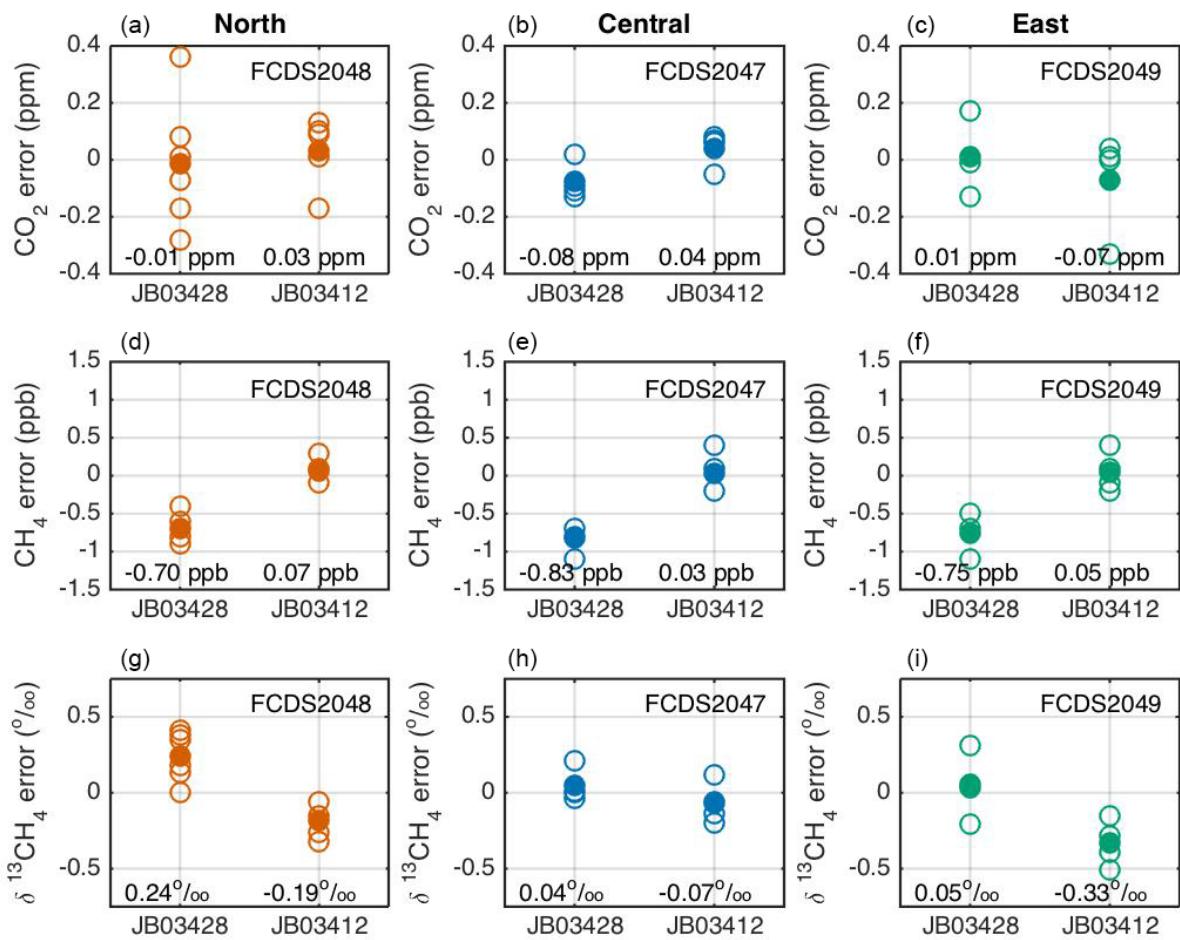

Figure 10. Results from round-robin style testing using two NOAA/INSTAAR tanks (JB03428: $-46.82 \%{ }^{13} \mathrm{CH}_{4}, 1895.3 \mathrm{ppb} \mathrm{CH}_{4}$, and 381.63 ppm $\mathrm{CO}_{2} ; \mathrm{JB} 03412:-45.29 \%{ }^{13} \mathrm{CH}_{4}, 2385.2 \mathrm{ppb} \mathrm{CH}_{4}$, and $\left.432.71 \mathrm{ppm} \mathrm{CO}_{2}\right)$ for $\mathrm{CO}_{2}(\mathbf{a}, \mathbf{b}, \mathbf{c}), \mathrm{CH}_{4}(\mathbf{d}, \mathbf{e}, \mathbf{f})$, and $\delta^{13} \mathrm{CH}_{4}(\mathbf{g}, \mathbf{h}$, i) for the analyzer deployed at the north tower (serial number FCDS2048; $\mathbf{a}, \mathbf{d}, \mathbf{g}$ ), at the central tower (serial number FCDS2047; b, e, h), and at the east tower (serial number FCDS2049; c, f, i). These tests were completed in the laboratory, post-deployment (March 2017). The analyzer deployed at the south tower (serial number FCDS2046) was not included in these tests. Open circles are individual tests, and filled circles are the means of the individual tests for each analyzer/constituent. The mean error for each analyzer/tank/constituent is indicated in the plots.

tank measuring $2385.2 \mathrm{ppb}$, and -0.83 to $-0.70 \mathrm{ppb} \mathrm{CH}_{4}$ for the NOAA/INSTAAR tank measuring $1895.3 \mathrm{ppb} \mathrm{CH}_{4}$. Therefore, there was a slight error in the slope of the linear calibration, possibly attributable to tank assignment errors. However, the error was well within the WMO recommendations for global studies of 2 ppb $\mathrm{CH}_{4}$ (GAW Report No. 229, 2016), and the range of NOAA/INSTAAR tanks encompassed the majority of the $\mathrm{CH}_{4}$ mole fraction observed during the study. We also note that the standard error for the means of the $\mathrm{CH}_{4}$ tests was $0.07-0.12 \mathrm{ppb}$. When averaging over the two round-robin tanks, the mean difference was -0.40 to $-0.32 \mathrm{ppm} \mathrm{CH}_{4}$ for the analyzers. For $\delta^{13} \mathrm{CH}_{4}$, the mean errors for each analyzer-tank pair were -0.33 to $0.24 \%$ o for these tanks, i.e., within the range of ambient isotopic ratio, and the standard errors were $0.05-0.10 \%$. The mean errors were -0.14 to $0.03 \%$ o for each analyzer.

\subsection{Side-by-side testing}

The precision and drift characteristics are not optimized for $\mathrm{CO}_{2}$ for the G2132-i analyzers, compared to the G2301 and G2401 analyzers, which measure mole fractions and not isotopic ratios. Whereas the spectral line for $\mathrm{CH}_{4}$ is the same between the two types of analyzers (Rella et al., 2015), for $\mathrm{CO}_{2}$, the absorbance of the spectral line used in the G2132-i analyzers is a factor of $11 \times$ less, meaning the precision is dramatically reduced. Although not central to the primary results of this project, the performance of the analyzers in terms of $\mathrm{CO}_{2}$ is important if the data are to be used as part of the continental-scale $\mathrm{CO}_{2}$ network. To test the performance of the G2132-i analyzers for consideration of the data for this use, G2301 and G2132-i (Picarro, Inc.) analyzers were run side by side for 1 month (June 2016) at the south tower. The sampling system for the G2132-i was as described in Sect. 5.2. A separate $1 / 4 \mathrm{in} .(0.64 \mathrm{~cm})$ tube was used for the G2301 analyzer, and an intercept calibration using the target tank was applied daily. The sample air for the G2301 analyzer was not dried, and the internal water vapor correction was used.

This testing resulted in mean differences of $0.06 \pm 0.41 \mathrm{ppm} \mathrm{CO}_{2}$ and $0.9 \pm 1.5 \mathrm{ppb} \mathrm{CH}_{4}$, with the G2132-i analyzer measuring slightly lower for both species. Here the standard deviation was based on the $10 \mathrm{~min}$ average calibrated values for the month for all times of the day. The standard error of the differences was $0.01 \mathrm{ppm} \mathrm{CO}_{2}$ and $0.02 \mathrm{ppb} \mathrm{CH}_{4}$. These results indicate that the performance 

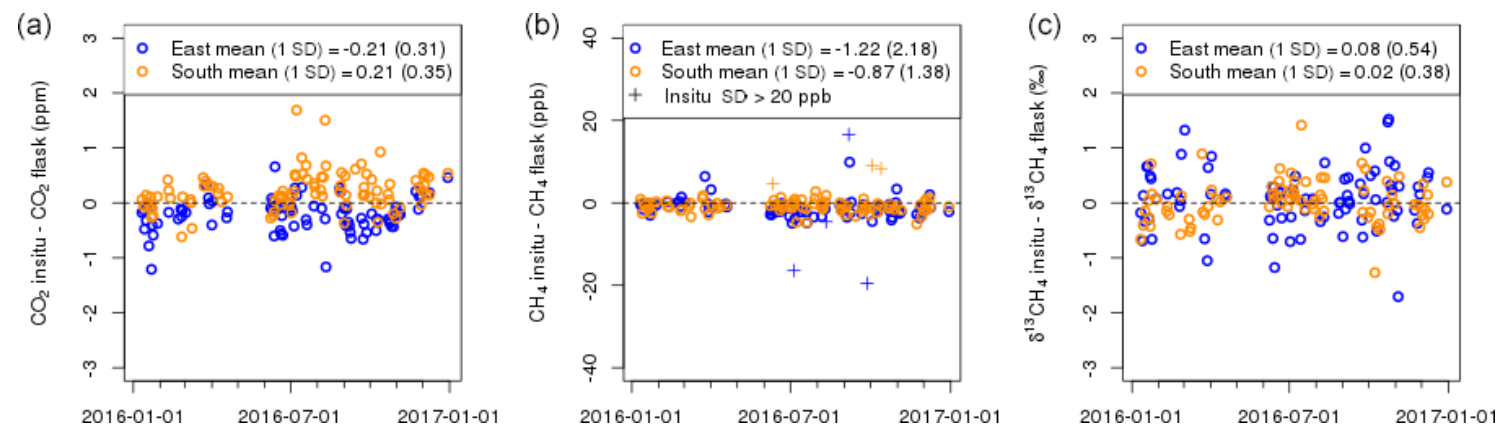

Figure 11. Afternoon in situ to flask differences for January-December 2016 for the east (blue) and the south towers (orange) for (a) $\mathrm{CO}_{2}$, (b) $\mathrm{CH}_{4}$, and (c) $\delta{ }^{13} \mathrm{CH}_{4}$. For $\mathrm{CH}_{4}$, data points with high temporal variability (standard deviation of raw $\sim 2 \mathrm{~s}$ data within the 10 min segments $>20 \mathrm{ppb}$ ) are indicated by "+" symbols and have been excluded. The standard deviation of the in-situ-to-flask differences are shown in parentheses on each plot. The standard errors, indicating an estimate of how far the sample mean is likely to be from the true mean, is $0.24 \mathrm{ppb} \mathrm{CH}_{4}, 0.03 \mathrm{ppm} \mathrm{CO}_{2}$, and $0.06 \%$ at the east tower and $0.14 \mathrm{ppb} \mathrm{CH}_{4}, 0.04 \mathrm{ppm} \mathrm{CO}_{2}$, and $0.04 \%$ at the south tower.

of the $\mathrm{G} 2132-\mathrm{i}$ is similar for $\mathrm{CO}_{2}$ and $\mathrm{CH}_{4}$ mole fractions, at least in terms of the long-term mean. In terms of utilizing the mole fraction data in atmospheric inversions, the multi-day mean afternoon differences are most appropriate. The 5-day mean afternoon difference for the month was $0.05 \pm 0.08 \mathrm{ppm} \mathrm{CO}_{2}$ and $-0.7 \pm 0.1 \mathrm{ppb} \mathrm{CH}_{4}$. The $\mathrm{G} 2132-\mathrm{i}$ analyzers are thus appropriate for use in the atmospheric inversions and in the global network where $0.1 \mathrm{ppm} \mathrm{CO}_{2}$ and $2.0 \mathrm{ppb} \mathrm{CH}_{4}$ have been identified as criteria. For these results, recall that the target tank was tested for a total of $30 \mathrm{~min}$ in 5 days. To optimize results on a daily timescale, sampling the target tank for $60 \mathrm{~min}$ per day would be preferable for improving $\mathrm{CO}_{2}$ results. We also note that round-robin testing of these instruments requires $60 \mathrm{~min}$ sampling per tank.

\subsection{Flask to in situ comparison}

In addition to the continuous G2132-i analyzers, the east and south towers were also equipped with NOAA flask sampling systems (Turnbull et al., 2012). These flask measurements were used for independent validation and error estimation of the continuous $\mathrm{CO}_{2}, \mathrm{CH}_{4}$, and $\delta^{13} \mathrm{CH}_{4}$ in situ measurements. In addition, the flasks were measured for a suite of species including $\mathrm{N}_{2} \mathrm{O}, \mathrm{SF}_{6}, \mathrm{CO}, \mathrm{H}_{2}$ (Dlugokencky et al., 2017), halo- and hydro-carbons (Montzka et al., 1993), and stable isotopes of $\mathrm{CH}_{4}$ (Vaughn et al., 2004). The flasks were filled over a $1 \mathrm{~h}$ time period in the afternoon (14:0015:00 LST), thereby yielding a more representative measurement than most flask sampling systems, which collect nearly instantaneous samples (e.g., $\sim 10$ s). Samples were collected only when winds were blowing steadily out of the west or north $\left(\sim 45-225^{\circ}\right)$ to ensure that the samples were sensitive to and representative of the broader Marcellus Shale gas production region that is the focus of this study. For the in situ data, 10 min segments were reported. These were averaged over the hour for comparison with the flask measurements. For $\mathrm{CH}_{4}$, data points with high temporal variability (stan- dard deviation of the 10 min means within the hour $>20 \mathrm{ppb}$ ) were excluded, on the basis that the ambient variability was large, making comparisons difficult.

For January-December 2016, the mean flask-to-in-situ $\mathrm{CH}_{4}$ difference at the east tower was $-1.2 \pm 2.2 \mathrm{ppb} \mathrm{CH}_{4}$, and at the south tower it was $-0.9 \pm 1.4 \mathrm{ppb} \mathrm{CH}_{4}$ (Fig. 11a). Here the standard deviation reported is that of the hourly flask-to-in-situ differences. Thus, at the south tower, for example, $67 \%$ of the sampled afternoons indicated differences for $\mathrm{CH}_{4}$ within $1.4 \mathrm{ppb}$ of the mean of $-0.9 \mathrm{ppb}$. The standard error was $0.24 \mathrm{ppb}$ at the east tower and $0.14 \mathrm{ppb}$ at the south tower. Thus, there is high confidence that the difference between the in situ and flask measurements at both towers is more compatible than the WMO recommendation. As for the side-by-side testing, the G2132-i analyzers were slightly lower than the "known", in this case, the flask results. The difference was, however, less than the target compatibility, and the flasks could in theory be biased.

Although $\mathrm{CO}_{2}$ is not the focus of this paper, the differences were $-0.21 \pm 0.31 \mathrm{ppm}$ for the east tower and $0.21 \pm 0.35 \mathrm{ppm}$ for the south tower (Fig. 11b). The standard error was $0.03 \mathrm{ppm}$ at the east tower and $0.04 \mathrm{ppm}$ at the south tower. The magnitude of $\mathrm{CO}_{2}$ differences was somewhat larger in the growing season. The mean flask-to-in-situ differences were thus larger than the WMO recommendation of $0.1 \mathrm{ppm}$, but at the extended compatibility goal of $0.2 \mathrm{ppm}$ $\mathrm{CO}_{2}$ (GAW Report No. 229, 2016).

For the isotopic ratio of methane, the mean flask-to-in-situ differences were $0.08 \pm 0.54$ and $0.02 \pm 0.38 \%$ at the east and south towers, respectively (Fig. 11c). The standard error of the differences was 0.06 and $0.04 \%$ at the east and south towers, respectively. The range of $\delta^{13} \mathrm{CH}_{4}$ throughout the project (including day and night) was relatively small: 1 standard deviation $(67 \%)$ of the data points are between $46.7-48.2 \%$, a range of $1.5 \%$. Errors for isotopic ratios outside the calibration range (further from the high and target calibration tanks) would likely be larger. For example, the 


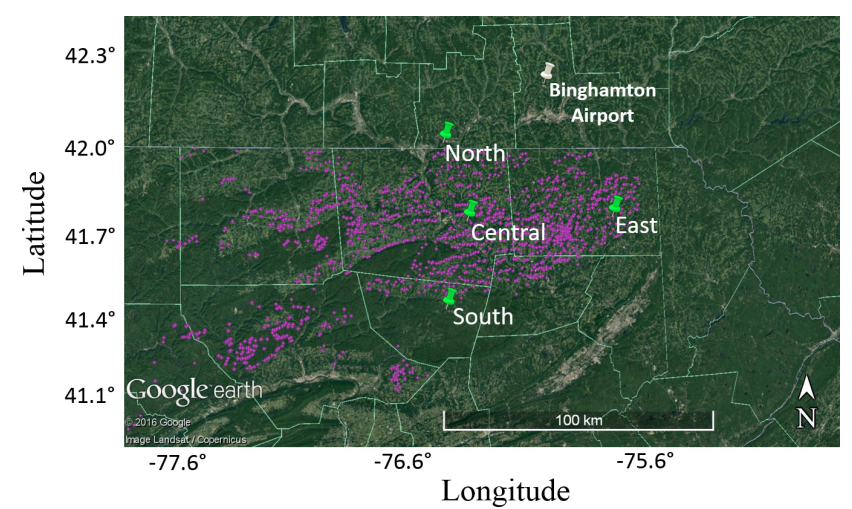

Figure 12. Map of Pennsylvania with permitted unconventional natural gas wells (magenta dots) and network of towers with methane and stable isotope analyzers (Picarro G2132-i). The east and south towers were also equipped with NOAA flask sampling systems. The Binghamton airport is also indicated.

mean error of the independent low tanks (averaging over all calibration cycles during a 1-month period) at the towers (Table 3) was $0.2-0.7 \%$.

\section{Network comparisons}

\subsection{Study area}

Four CRDS isotopic $\mathrm{CH}_{4}$ analyzers (G2132-i, Picarro, Inc.) were deployed on commercial towers 46-61 m a.g.l. in northeast Pennsylvania (Fig. 12). The south and north towers were located on the southern and northern edges of the unconventional gas well region, respectively, and were intended to measure background values depending on the wind direction. Measurements began in May 2015, but a complete set of field tanks necessary for calibration of $\delta^{13} \mathrm{CH}_{4}$ was not deployed until January 2016. The central tower measured only mole fractions for the period June-December 2016. For intertower comparisons, we focused on the period January-May 2016, when all sites measured both $\mathrm{CH}_{4}$ and $\delta^{13} \mathrm{CH}_{4}$. Raw and hourly averaged, calibrated data files are available online (Miles et al., 2017).

\subsection{Inter-network differences in $\mathrm{CH}_{4}$ and $\delta^{13} \mathrm{CH}_{4}$}

A background value is required to calculate differences in $\mathrm{CH}_{4}$ and $\delta^{13} \mathrm{CH}_{4}$. For this simple analysis, we chose a single tower to represent the background for the entire period. The predominant wind direction for the Marcellus region is from the west (Fig. 13). For westerly winds, the south tower is a reasonable choice for a background tower. The south tower measured the lowest overall mean afternoon methane mole fraction (1960.2 ppb $\mathrm{CH}_{4}$ ). The mean afternoon methane mole fractions of the other towers, averaged only when data for the south tower exist, were 8.7, 7.0, and $2.9 \mathrm{ppb}$ higher

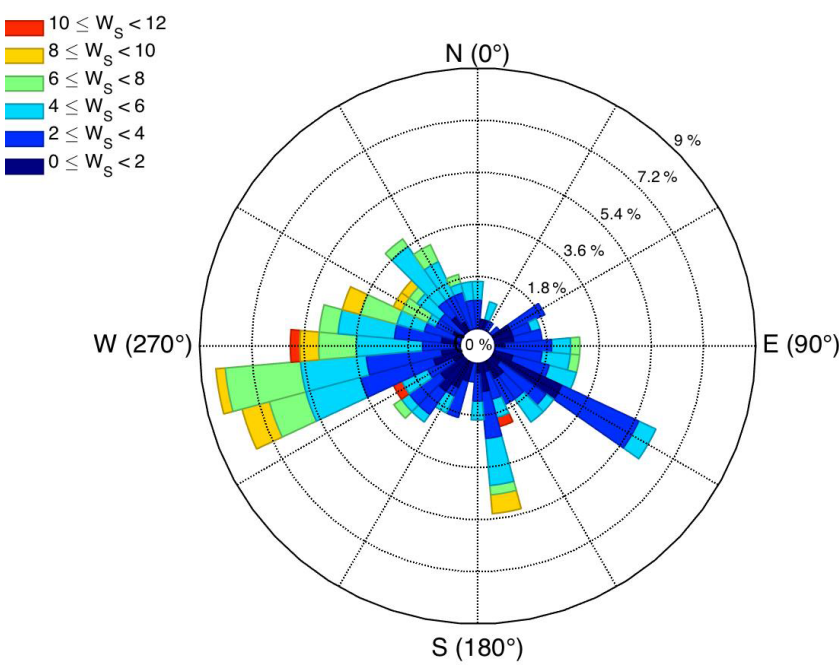

Figure 13. Wind rose for surface station at Binghamton, NY, airport for the period April 2015-April 2016 (using the mean of the afternoon hours for each day). The magnitude of wedges indicates relative frequency for each wind direction, and the wind speeds are indicated by color. These afternoon means were based on hourly reported measurements. For the hourly measurements, calm winds $\left(<1.6 \mathrm{~m} \mathrm{~s}^{-1}\right)$ were not categorized by direction and thus were not included in the afternoon mean. For the hourly measurements, calm winds $\left(<1.6 \mathrm{~m} \mathrm{~s}^{-1}\right)$ were reported as zero and were included in the afternoon mean.

at the north, central, and east towers, respectively. For future analysis, a wind-direction-dependent background tower (south or north) could be considered, but the north tower did have the largest mean enhancement in $\mathrm{CH}_{4}$ mole fraction as compared to the south tower. As noted by Barkley et al. (2017), the area encompassing southwestern Pennsylvania and northeastern West Virginia contains large sources of $\mathrm{CH}_{4}$, with emissions from conventional gas, unconventional gas, and coal mines all having significant contributions to the total. These large sources complicated the interpretation of the signals, as does changing wind direction. For this overview analysis, we calculated differences above the south background tower to determine overall signal strength to compare with our target compatibility. We first examine the afternoon (defined here are 17:00-20:59 UTC), when the atmospheric is well mixed, allowing simpler interpretation of the measurements and more tractable modeling. We then consider non-afternoon hours, when the atmosphere is less mixed and signals are typically larger.

In the first set of plots, we focus on the majority of the afternoon data points by truncating the scale for the probability distribution functions of methane mole fraction and isotopic ratio (Fig. 14a, b, d, e, g, and h). The averaging interval of the individual data points was $10 \mathrm{~min}$, and the data were afternoon-only (17:00-20:59 UTC, 12:00-15:59 LST) for the time period January-May 2016. The median differences for both isotopic ratio ( -0.15 to $0.12 \%$ ) and methane 

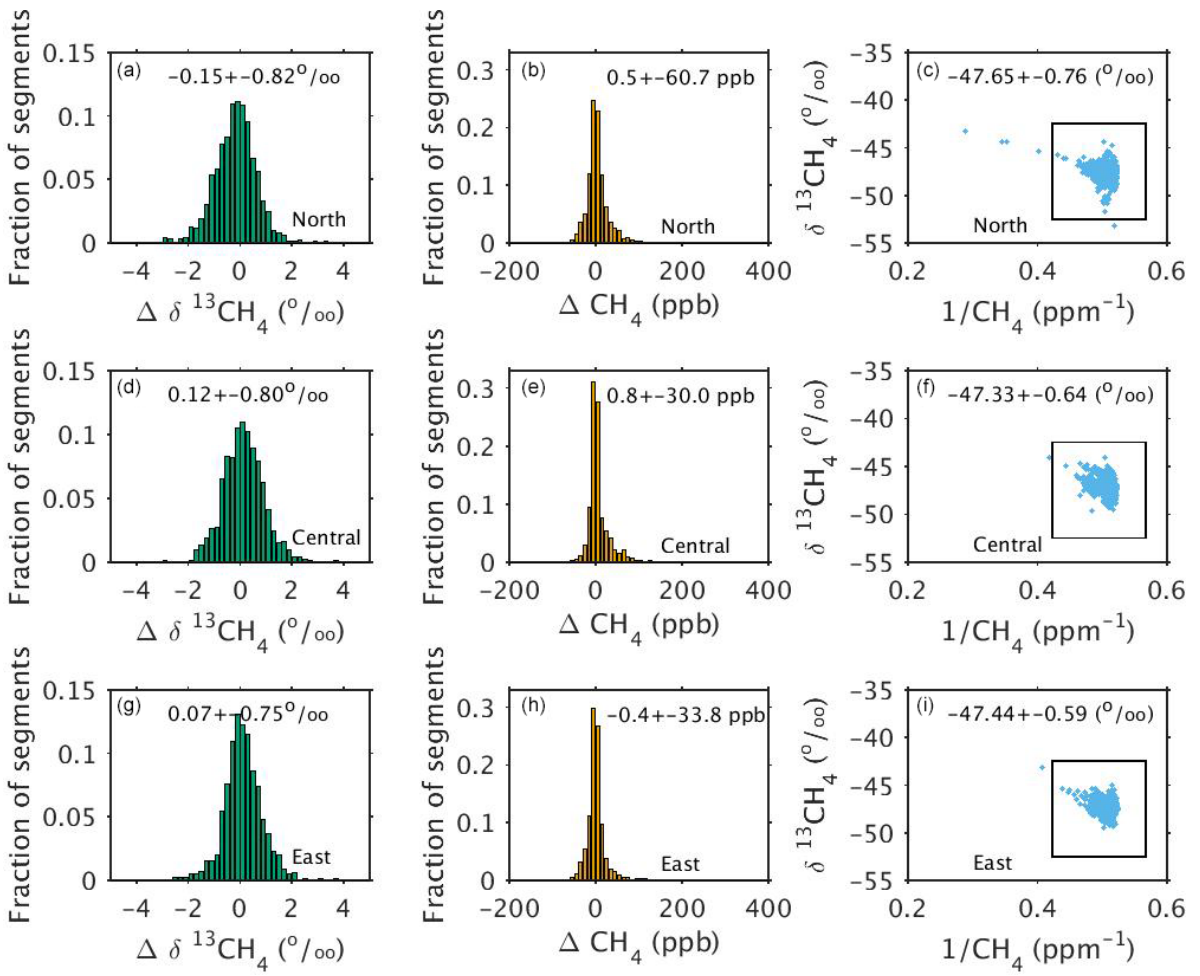

Figure 14. Probability distribution function of measured isotopic ratio differences from the background south tower $\left(\Delta \delta^{13} \mathrm{CH}_{4}\right)$ for the (a) north, (d) central, and (g) east towers for afternoon hours (17:00-20:59 UTC, 12:00-15:59 LST). The averaging interval of the individual data points for all plots is $10 \mathrm{~min}$, and the time period is January-May 2016. The bin size for (a), (d), and (g) is $0.2 \%$. The median and standard deviation of the differences are indicated on the plots. Probability distribution function of measured methane mole fraction enhancements $\left(\Delta \mathrm{CH}_{4}\right)$ for the (b) north, (e) central, and (h) east towers. Note that the scale for (b), (e), and (h) has been truncated to focus on majority of the data points. The bin size is $10 \mathrm{ppb} \mathrm{CH}_{4}$. Keeling plots for the (c) north, (f) central, and (i) east towers. The black box in each plot indicates the approximate scale of the corresponding isotopic ratio difference and methane mole fraction enhancement plots. The median and standard deviation of the isotopic ratios at each tower are indicated on the plots. Note that the Allan deviation for 10 min means at ambient mole fractions was $0.4 \%$, and this decreases with increasing mole fraction.

mole fraction (less than $1 \mathrm{ppb}$ ) were less in magnitude than the compatibility of the analyzers. This result is generally consistent with the results of Barkley et al. (2017), who found the emission rate of methane due to natural gas extraction activities to be very low, $0.36 \%$ of total production. The standard deviation of $10 \mathrm{~min}$ segments of isotopic ratio differences was $0.8 \%$ at each of the towers. We note that the Allan standard deviation for $10 \mathrm{~min}$ averaging times for ambient levels of methane was $0.4 \% o \delta^{13} \mathrm{CH}_{4}$. The standard deviation of the daily afternoon averages (rather than $10 \mathrm{~min}$ averages) was $0.6-0.7 \%$. Thus the observed width of the distribution appears to be persistent throughout the afternoon and not merely measurement noise. For isotopic ratio, 43$54 \%$, depending on the tower, of the $10 \mathrm{~min}$ segments were greater than $0.6 \%$ in magnitude $(3 \times$ the target compatibility; Fig. 14a, d, and g) and are thus detectable by the analyzers. The standard deviations of the methane mole fraction differences were $60.7,30.0$, and $33.8 \mathrm{ppb}$ for the north, central, and east towers, respectively (Fig. 14b, e, and h). Differences greater than $6 \mathrm{ppb} \mathrm{CH}_{4}$ in magnitude $(3 \times$ the target compat- ibility) were indicated by $57-66 \%$ of the data points for the north, central, and east towers (Fig. 14b, r, and h) and are thus detectable. The majority of afternoon data points indicated relatively few local sources of contamination.

There are, however, a few outliers during the time period with large values above the background tower during the afternoon hours (up to $1500 \mathrm{ppb}$ enhancement at the north tower). The isotopic as a function of inverse methane mole fraction at each non-background tower is shown in Fig. 13c, $\mathrm{f}$, and i. While the range of measured isotopic ratios is large, the majority of the 10 min means lie close to the ambient values: the standard deviation of the 10 min means of the measured isotopic ratios during the afternoon was $0.6-0.8 \%$.

During non-afternoon hours (00:00-16:59 and 21:0023:59 UTC), the median isotopic ratio difference from the south tower were still indistinguishable from zero (Fig. 15a, $\mathrm{d}$, and $\mathrm{g}$ ). The median methane mole fraction enhancement was slightly higher than during the afternoons, at 3.5, 6.8, and $9.8 \mathrm{ppb}$ for the north, central, and east towers, respectively (Fig. 15b, e, and h). There were, however, more out- 

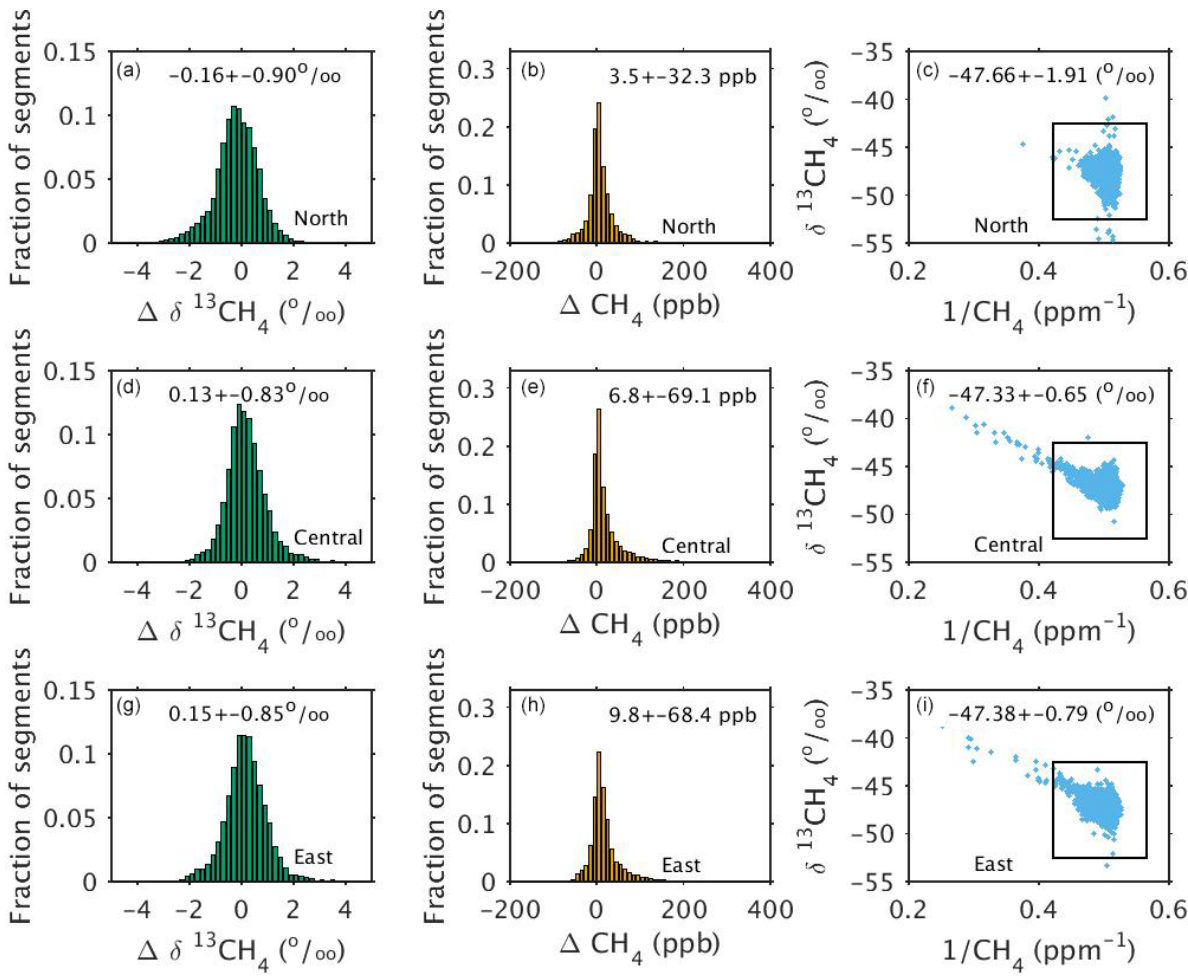

Figure 15. Probability distribution function of measured isotopic ratio differences from the background south tower $\left(\Delta \delta^{13} \mathrm{CH}_{4}\right)$ for the (a) north, (d) central, and (g) east towers for all times of data excluding the afternoon hours shown in Fig. 14. The averaging interval of the individual data points for all plots is $10 \mathrm{~min}$, and the time period is January-May 2016. The bin size for (a), (d), and (g) is $0.2 \%$. The median and standard deviation of the differences are indicated on the plots. Probability distribution function of methane mole fraction enhancements $\left(\Delta \mathrm{CH}_{4}\right)$ for the (b) north, (e) central, and (h) east towers. Note that the scale for (b), (e), and (h) has been truncated to focus on majority of the data points. The bin size is $10 \mathrm{ppb} \mathrm{CH}_{4}$. Keeling plots for the (c) north, (f) central, and (i) east towers. The black box in each plot indicates the approximate scale of the corresponding isotopic ratio difference and methane mole fraction enhancement plots. The median and standard deviation of the isotopic ratios at each tower are indicated on the plots. Note that the Allan deviation for 10 min means at ambient mole fractions was $0.4 \%$, and this decreases with increasing mole fraction.

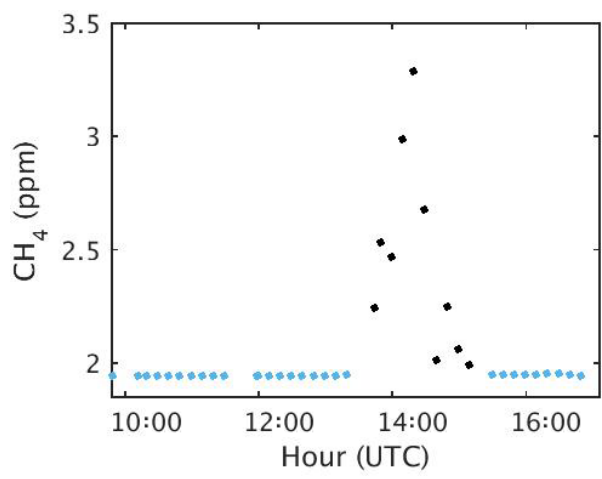

Figure 16. Time series of $\mathrm{CH}_{4}$ encompassing one of the eight peaks in $\mathrm{CH}_{4}$ at the central tower (DOY 55) for which the Keeling plot approach was applied. The averaging interval of the individual points was $10 \mathrm{~min}$, and periods during which field tanks were sampled were excluded from the plot. The linear fit was calculated using the points clearly within the plume (black dots). liers, particularly at the central tower (Fig. 15c, f, and e). Applying a best-fit line to all of the data shown in Fig. 14f gave a poor correlation coefficient $\left(r^{2}=0.22\right)$ because there were many data points with no local sources.

\subsection{Keeling plots}

Keeling plots (Keeling, 1961; Röckmann et al., 2016) are used to infer the isotopic ratio of the methane source as the intercept of the best-fit line of the isotopic ratio as a function of the inverse methane mole fraction. We used this approach to estimate the source isotopic ratio of the eight largest peaks observed during non-afternoon hours at the central tower. The time series of $\mathrm{CH}_{4}$ encompassing the peak observed on day of year (DOY) 55 is shown in Fig. 16, as an example. The time during which the tower was in the plume was clear (lasting about $1.5 \mathrm{~h}$ ), and only those points were included in the calculation of the linear fit.

The Keeling plots for each of the eight largest peaks in the non-afternoon methane data are shown in Fig. 17. The intercepts of the best-fit lines for the peaks indicate that the 

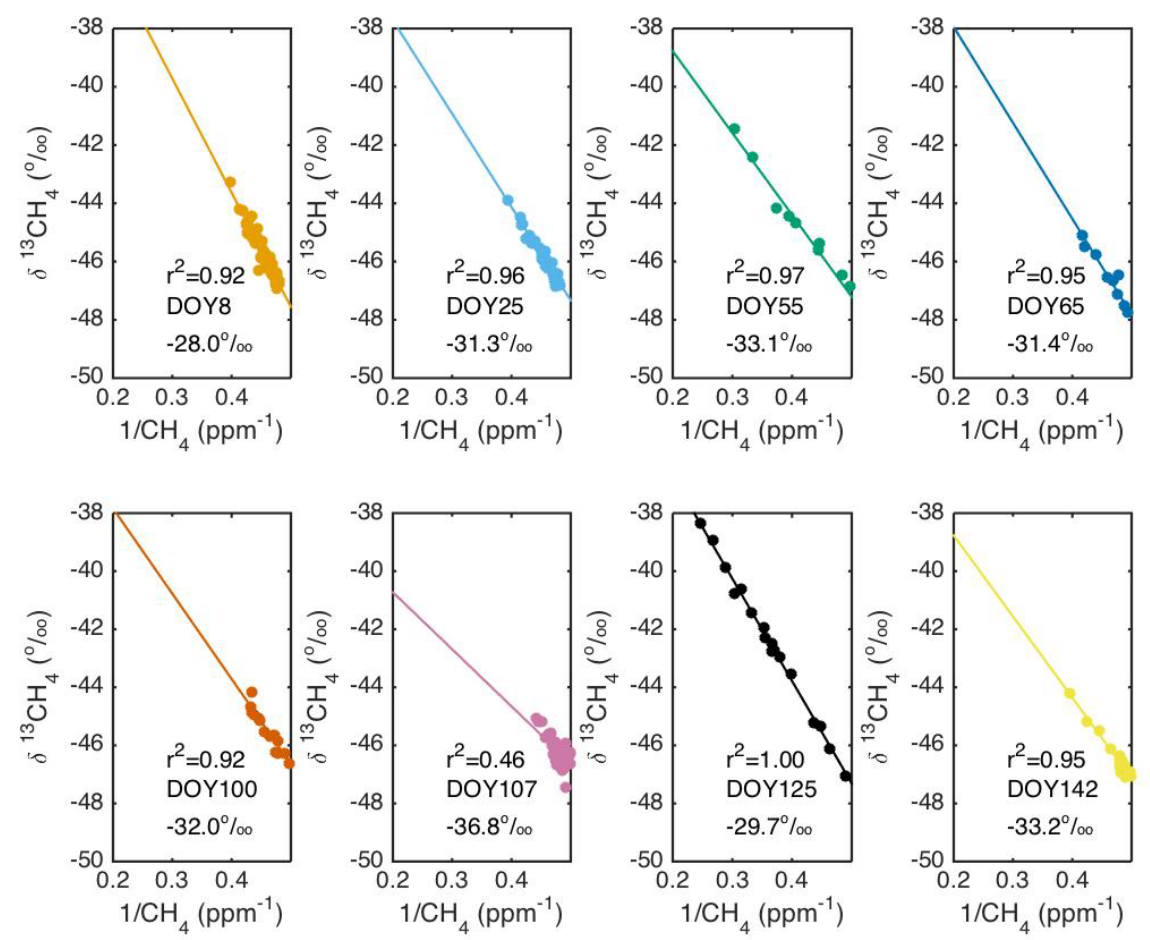

Figure 17. Keeling plots for the central tower for the eight largest peaks in the non-afternoon methane time series. Black lines indicate the best-fit lines. Correlation coefficients $\left(r^{2}\right)$, day of year (DOY), and $y$ intercepts are indicated in the plots.

sources contributing to the peaks have a mean isotopic ratio of $-31.2 \pm 1.9 \%$. The correlation coefficients were high $\left(r^{2}=0.92-1.0\right)$ except for one peak, which was excluded from the statistics. When propagating a potential error (attributable of analyzer uncertainty) of $0.2 \%$ at the heavy end of the Keeling plots and $-0.2 \%$ at the light end, and vice versa, the potential range of the mean is from -32.0 to $-30.4 \%$.

Compared to mobile measurements near the ground, for example, the footprints of towers are large, which is ideal for determining regional emissions. But the emissions sources with specific isotopic signatures are diluted by mixing, making the enhancements above background small, particularly for this region/time period with small leakage rates. For these eight non-afternoon peaks at the central tower, the enhancements over background were 334.1-2007.8 $\mathrm{ppb} \mathrm{CH}_{4}$, and the differences of isotopic ratio were -2.5 to $-8.7 \%$.

\section{Discussion}

In this paper, we present the methods used to calibrate a network of four CRDS methane isotopic ratio analyzers ( $\mathrm{Pi}$ carro G-2132i). Evaluation of the calibration results using an independent tank, round-robin style testing, and flask comparisons showed that the analyzers are compatible within $0.2 \%$. The calibration required consideration of (1) the isotopic ratio linear calibration, (2) the mole fraction depen- dence of the isotopic ratio calibration (using high and ambient mole fraction tanks), (3) the correction due to ethane cross-interference (using one tank without ethane and one tank with ambient ethane), and (4) drift in the $\mathrm{CO}_{2}$ and $\mathrm{CH}_{4}$ mole fractions (using at least one tank near-ambient isotopic ratio and mole fraction). The isotopic ratios and $\mathrm{CH}_{4}$ mole fractions of these tanks as used in the present deployment are graphically represented in Fig. 18a. Prior to implementation of the improved field tank testing strategy, the high and low tanks were tested for 26 and 52 min day $^{-1}$ (excluding transition time between gases), as listed in Table 4. The testing times throughout each day for the high and low standards are sufficient for Allan deviation $<0.1 \%$, but neither of those tanks were at ambient ranges of $\delta^{13} \mathrm{CH}_{4}$. If the calibrations and analyzer response were both linear, we would expect negligible errors in the target tank if kept independent, but we found a bias between -0.3 and $-0.8 \%$, which is very large compared to the ambient differences observed (1 standard deviation of the tower measurements at all times of day were between -48.2 and $-46.7 \%$ o). Thus, we instead chose to minimize mean error at ambient values (target tank) rather than at the isotopic ratios of the low tanks $(-23.9 \%$ ). This procedure added noise to the ambient data because the daily sampling time for the target tank was only 6 min day $^{-1}$. On 3 December 2016, we implemented an improved tank testing strategy, primarily by increasing the testing time for the target tank to 54 min day $^{-1}$. 
Table 4. Possible field tanks and sampling strategies, including those employed in the present study. The "Improved strategy" column suggests a possible strategy in which three field tanks and one independent tank are employed, and thus laboratory calibration is not required. Estimated tank testing times (excluding transition times) are listed for various compatibility requirements.

\begin{tabular}{|c|c|c|c|}
\hline & $\begin{array}{l}\text { Present study prior to } 3 \\
\text { December } 2016\end{array}$ & $\begin{array}{l}\text { Present study } 3 \text { December } \\
2016 \text { and thereafter }\end{array}$ & Improved strategy \\
\hline $\begin{array}{l}\text { Laboratory calibration } \\
\text { needed? }\end{array}$ & Yes, for linear calibration & Yes, for linear calibration & No \\
\hline $\begin{array}{l}\text { High } \mathrm{CH}_{4} \text { mole fraction } \\
\operatorname{tank}(\mathrm{s})\end{array}$ & $\begin{array}{l}\text { HIGH (10 ppm, } \\
\left.-38.3 \% o, 26 \text { min day }^{-1}\right) \\
-\end{array}$ & $\begin{array}{l}\text { HIGH }(10 \mathrm{ppm}, \\
\left.-38.3 \% \text {, } 10 \text { min day }^{-1}\right) \\
-\end{array}$ & $\begin{array}{l}\text { HIGH }\left(10 \mathrm{ppm},-38.3 \text { to }-44 \%, 8 \mathrm{~min} \mathrm{day}^{-1} \text { for }\right. \\
0.1 \% \text { Allan deviations, } 1 \text { for } 0.2 \%, 1 \text { for } 0.4 \% \text { ) } \\
\text { HIGH ( } 10 \mathrm{ppm} \text {, } \\
-54.5 \text { to }-52 \%, 8 \text { min day }^{-1} \text { for } 0.1 \% \text { Allan devia- } \\
\text { tions, } 1 \text { for } 0.2 \%, 1 \text { for } 0.4 \% \text { ) }\end{array}$ \\
\hline \multirow[t]{2}{*}{$\begin{array}{l}\text { Low } \mathrm{CH}_{4} \text { mole fraction } \\
\text { tanks }\end{array}$} & $\begin{array}{l}\text { LOW }(2 \mathrm{ppm}, \\
\left.-23.9 \%, 81 \min ^{-1}\right) \\
\text { independent }\end{array}$ & $\begin{array}{l}\text { LOW }(2 \mathrm{ppm}, \quad-23.9 \% \text { } \\
\left.54 \min ^{-1}\right) \\
\text { indepen- }\end{array}$ & $\begin{array}{l}\text { LOW ( } 2.1 \mathrm{ppm},-46.5 \% \text { (ambient), } 120 \mathrm{~min}^{-1}{ }^{-1} \text { for } \\
0.1 \% \text { Allan deviations, } 60 \text { for } 0.2 \% \text { o, } 8 \text { for } 0.4 \% \text { ) }\end{array}$ \\
\hline & $\begin{array}{l}\text { TARGET ( } 2 \mathrm{ppm}, \\
\left.-47.2 \% o, 6 \text { min day }^{-1}\right)\end{array}$ & $\begin{array}{l}\text { TARGET ( } 2 \mathrm{ppm}, \\
\left.-47.2 \% o, 54 \text { min day }^{-1}\right)\end{array}$ & $\begin{array}{l}\text { TARGET ( } 1.9 \mathrm{ppm},-47.5 \% \text { (ambient), } 120 \mathrm{~min}^{-1 a y}{ }^{-1} \\
\text { for } 0.1 \% \text { Allan deviations, } 60 \text { for } 0.2 \% \text {, } 8 \text { for } 0.4 \% \text { ) } \\
\text { independent }\end{array}$ \\
\hline Notes & & $\begin{array}{l}\text { Reduced noise in calibra- } \\
\text { tion due to increased tar- } \\
\text { get tank testing time }\end{array}$ & $\begin{array}{l}\text { Does not necessarily require laboratory calibration of } \\
\text { analyzers. Range of ideal isotopic ratios for the high } \\
\text { tanks is given. Utilizing the isotopic ratios of com- } \\
\text { mercially available bottles for spiking (i.e., }-38.3 \text { and } \\
-54.5 \% \text { ) may avoid the need for laboratory calibration } \\
\text { of these tanks. Using the range of the near-ambient iso- } \\
\text { topic ratio of low/target tanks (but not exactly the same } \\
\text { isotopic ratio, and preferably not exactly the same mole } \\
\text { fraction) is more accurate reflection of compatibility, } \\
\text { and range of the isotopic ratio of the high tanks better } \\
\text { encompasses expected values. For applications with re- } \\
\text { duced compatibility requirements (e.g., } 0.4 \% \text { ), utiliz- } \\
\text { ing low/target tanks at commercially available }-38.3 \\
\text { and }-54.5 \% \text { may be sufficient. It is advantageous to } \\
\text { distribute field tank testing throughout the day, to avoid } \\
\text { not sampling ambient air for long periods and to mea- } \\
\text { sure potential changes in analyzer response. }\end{array}$ \\
\hline
\end{tabular}

Our recommendation for future similar studies is to choose both target and low tanks closer to the expected range of isotopic ratios, in addition to being near-ambient $\mathrm{CH}_{4}$ mole fractions. For example, suggested values for the low and tar-

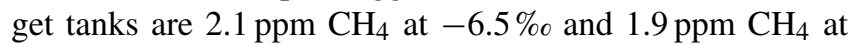
$-47.5 \%$ (Table 4 and Fig. 18b). The testing time required is dependent upon the compatibility goals. After implementing our improved tank testing time strategy, we tested each target and low tank for about an hour per day, to achieve Allan deviations of $0.2 \%$. Source attribution using mobile measurements, rather than tower measurements, for example, is less demanding in terms of compatibility needed, due to the relatively large ambient signals typically encountered. The estimated testing time required to achieve Allan deviations less than $0.4 \%$, for example, is $8 \mathrm{~min}$. In general, it is desirable to distribute the tank testing time throughout the time period, in our case, 1 day. In this case, persistent changes in analyzer response over the day, if any, would be averaged over rather than an extreme value used in the calibration. This procedure also avoids not sampling the ambient air for extended periods. We did not find any evidence of variability in the calibrations on scales less than 1 day, compared to the precision possible given our tank testing times, but this possibility could be further explored by testing the field tanks for longer periods of time.

The high tanks used in this network contained methane with about $-38.3 \%$ o $\mathrm{CH}_{4}$. This specific isotopic ratio is available commercially and, depending on the compatibility goals of the project, may not require laboratory calibration of the tank. For our case, however, it may have been beneficial to utilize isotopic ratios closer to the observed range, perhaps $-44 \%$ (Table 4). Another possibility is to add an additional high tank (Fig. 18b) in the range of -54.5 to $-52 \%$ o (with $-52 \%$ more closely bracketing the observed isotopic ratios in the present study). In this case, laboratory linear calibration of the analyzers is not necessarily required. Both the slope and intercept of the linear calibration can be adjusted in field, rather than just the intercept, which may improve the calculated accuracy and precision. However, the laboratory calibration in the present study utilized four different isotopic ratios, rather than two, and it is unknown which is more im- 

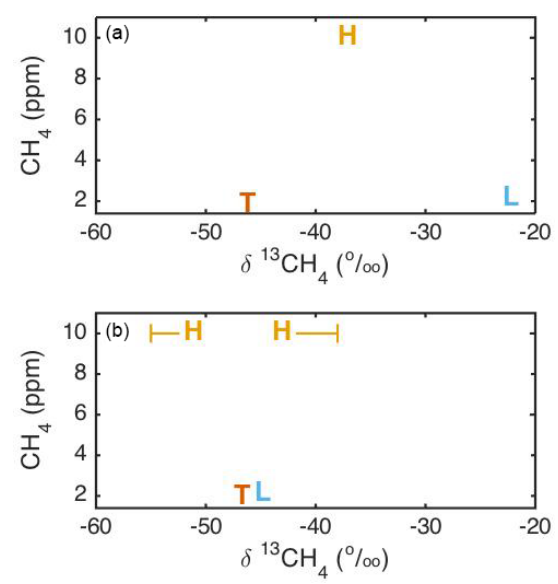

Figure 18. Graphical representation of the field tanks used in the present study (a), and for an improved strategy (as in Table 4; b). Orange "H" symbols indicate high mole fraction tanks, blue "L" symbols indicate low mole fraction tanks, and red "T" symbols indicate target tanks. Lines in (b) indicate range of isotopic values desirable for the high tanks.

portant - improving linear calibration frequency or avoiding over-constraining the calibration.

In this paper, we calibrated the total $\mathrm{CH}_{4}$ and the isotopic ratio of methane. An alternative calibration approach is to separately calibrate the individual isotopologues (in this case, ${ }^{13} \mathrm{CH}_{4}$ and ${ }^{12} \mathrm{CH}_{4}$ dry mole fractions), as has been applied to Fourier transform infrared and isotope ratio infrared spectrometers measuring $\delta^{13} \mathrm{C}$ and $\delta^{18} \mathrm{O}$ of $\mathrm{CO}_{2}$ in air (Griffith et al., 2012; Wen et al., 2013; Flores et al., 2017). This approach has the advantage of simple calibration equations but has the disadvantage that the quantities of interest (e.g., total mole fraction and isotopic ratio) are calculated rather than directly calibration. Like the approach applied in this paper, it also requires at least two standard tanks and could utilize an independent tank for testing. Rella et al. (2015) list further practical reasons to calibrate $\delta^{13} \mathrm{CH}_{4}$, including the lack of primary standards for ${ }^{13} \mathrm{CH}_{4}$. However, a comparison of performance using each of these techniques on the same data set would be beneficial.

The signals observed in the study region were generally small, but the isotopic ratio differences were larger than would be expected based on the methane mole fraction enhancements from local sources. For afternoon hours at the central tower, for example, $43 \%$ of the differences in $\delta^{13} \mathrm{CH}_{4}$ were detectable above background with magnitudes $>0.6 \%$, 3 times the analyzer compatibility. For a thermogenic source with isotopic ratio of $-35 \%$ and a background isotopic ratio of $-47 \%$, and assuming a measured $\mathrm{CH}_{4}$ mole fraction of $2000 \mathrm{ppb}$, a measured isotopic ratio difference of $-0.6 \%$ o corresponds to a $100 \mathrm{ppb}$ peak in $\mathrm{CH}_{4}$ above background, following Eq. (1). Enhancements in $\mathrm{CH}_{4}$ of $100 \mathrm{ppb}$ were rarely encountered, however (Fig. 14b, e, and h). Using
Eq. (1) to predict differences of isotopic ratio based on the observed methane mole fraction enhancements corresponded to only $3 \%$ of the isotopic ratio differences expected to be $>0.6 \%$ in magnitude. Thus during the afternoon hours, most of the deviations from background were not likely directly from local sources. These larger-than-expected differences in isotopic ratio are not primarily attributable to analyzer noise. The Allan deviation (Fig. 2) is $0.4 \%$ o for 10 min means at ambient mole fractions of $2 \mathrm{ppm} \mathrm{CH}_{4}$. We also note that we focused on the period January-May 2016 in this work. Larger differences were observed in the latter half of 2016.

During the morning hours, however, several peaks resulting from local sources were observed. The mean source isotopic signal indicated by Keeling plot analysis of the eight largest peaks at the central tower was $-31.2 \pm 1.9 \%$, fairly heavy even for oil/natural gas sources. In general, the isotopic signature for natural gas sources varies from region to region, and even within one region. The mean isotopic ratio of methane in gas wells in the northeastern Pennsylvania section of the Marcellus region has been shown to vary by depth, from $-43.42 \%$ with a standard deviation of $6.84 \%$ o for depths of 0 to $305 \mathrm{~m}$, to $-32.46 \%$ with a standard deviation of $3.84 \%$ o for depths greater than $1524 \mathrm{~m}$ (Baldassare et al., 2014). Similarly, Molofsky et al. (2011) found that the isotopic signatures of gases from the deeper layers of the Marcellus Shale in Susquehanna County, Pennsylvania, to be heavier than the shallower Middle and Upper Devonian deposits, with values for the deep layers ranging from -30 to $-21 \%$. Thus, the source signature determined here is consistent with a natural gas source originating from deep wells in the Marcellus region. The peaks occurred during the morning hours, when the boundary layer is typically stable, making modeling more difficult, and the winds prior to the peaks were not from a consistent direction. Determination of the location of the specific emitter(s) contributing to these peaks is thus beyond the scope of this paper. Based on the lack of consistent wind direction, it seems likely that more than one location (with potentially different source signatures) contributed to these peaks. We note that the Keeling plot approach to determine source isotopic signatures far from the point of emission will be difficult to apply in regions without sources that are significantly depleted or enriched in ${ }^{13} \mathrm{CH}_{4}$ compared to ambient.

For determination of the source signature for a specific known location, the tower-based approach is not ideal. Instead the strength of the tower-based approach lies in covering larger areas and many potential source locations, and for longer periods of time than is feasible by other approaches. The instrumental performance demonstrated here could be used to disaggregate methane sources in areas of stronger enhancements and differing source isotopic signatures. Networks of high-temporal-resolution methane isotopic ratio data have the potential to constrain regional methane budgets when used within a modeling framework. 
Data availability. In situ tower atmospheric methane mole fraction and isotopic ratio of methane data, Marcellus Shale gas region, Pennsylvania, USA, 2015-2016. Data set available online (http://datacommons.psu.edu) from The Pennsylvania State University Data Commons, University Park, Pennsylvania, USA. https://doi.org/10.18113/D3SG6N (Miles et al., 2017).

Competing interests. TL, SJR, NLM, and KJD are co-owners of a related company, Carbon Now Cast, LLC.

Special issue statement. This article is part of the special issue "The 10th International Carbon Dioxide Conference (ICDC10) and the 19th WMO/IAEA Meeting on Carbon Dioxide, other Greenhouse Gases and Related Measurement Techniques (GGMT-2017) (AMT/ACP/BG/CP/ESD inter-journal SI)". It is a result of the 19th WMO/IAEA Meeting on Carbon Dioxide, Other Greenhouse Gases, and Related Measurement Techniques (GGMT-2017), Empa Dübendorf, Switzerland, 27-31 August 2017.

Acknowledgements. The authors thank Bruce V. Vaughn and Sylvia Englund Michel (Institute of Arctic and Alpine Research, University of Colorado) for providing analysis of methane isotopic ratios of the flask data and for advice regarding gas handling techniques involving isotopic ratios. The authors also acknowledge Robert P. Barkley (Tunkhannock Area Middle School) for his contributions to maintaining instrumentation at the tower sites. This work was funded by the Department of Energy National Energy Technology Laboratory (DE-FOA-0000894).

Edited by: Martin Steinbacher

Reviewed by: David Lowry and one anonymous referee

\section{References}

Allan, D. W.: Statistics of atomic frequency standards, P. IEEE, 54, 221-230, 1966.

Alvarez, R. A., Pacalab, S. W., Winebrake, J. J., Chamedies, W. L., and Hamburg, S. P.: Greater focus needed on methane leakage from natural gas infrastructure, P. Natl. Acad. Sci. USA, 109, 6435-6440, https://doi.org/10.1073/pnas.1202407109, 2012.

Andrews, A. E., Kofler, J. D., Trudeau, M. E., Williams, J. C., Neff, D. H., Masarie, K. A., Chao, D. Y., Kitzis, D. R., Novelli, P. C., Zhao, C. L., Dlugokencky, E. J., Lang, P. M., Crotwell, M. J., Fischer, M. L., Parker, M. J., Lee, J. T., Baumann, D. D., Desai, A. R., Stanier, C. O., De Wekker, S. F. J., Wolfe, D. E., Munger, J. W., and Tans, P. P.: $\mathrm{CO}_{2}, \mathrm{CO}$, and $\mathrm{CH}_{4}$ measurements from tall towers in the NOAA Earth System Research Laboratory's Global Greenhouse Gas Reference Network: instrumentation, uncertainty analysis, and recommendations for future high-accuracy greenhouse gas monitoring efforts, Atmos. Meas. Tech., 7, 647687, https://doi.org/10.5194/amt-7-647-2014, 2014.

Baldassare, F. J., McCaffrey, M. A., and Harper, J. A.: A geochemical context for stray gas investigations in the northern Appalachian Basin: Implications of analyses of natural gases from
Neogene-through Devonian-age strata, Am. Assoc. Petr. Geol. B., 98, 341-372, https://doi.org/10.1306/06111312178, 2014.

Barnes, I.: Tropospheric Chemistry and Composition: Sulfur Chemistry, Organic in Encyclopedia and Atmospheric Sciences, edited by: North, G. R., Pyle, J. A., and Zhang, F., Elsevier, 6, 257, 2015.

Barkley, Z. R., Lauvaux, T., Davis, K. J., Deng, A., Miles, N. L., Richardson, S. J., Cao, Y., Sweeney, C., Karion, A., Smith, M., Kort, E. A., Schwietzke, S., Murphy, T., Cervone, G., Martins, D., and Maasakkers, J. D.: Quantifying methane emissions from natural gas production in north-eastern Pennsylvania, Atmos. Chem. Phys., 17, 13941-13966, https://doi.org/10.5194/acp-1713941-2017, 2017.

Chen, H., Winderlich, J., Gerbig, C., Hoefer, A., Rella, C. W., Crosson, E. R., Van Pelt, A. D., Steinbach, J., Kolle, O., Beck, V., Daube, B. C., Gottlieb, E. W., Chow, V. Y., Santoni, G. W., and Wofsy, S. C.: High-accuracy continuous airborne measurements of greenhouse gases $\left(\mathrm{CO}_{2}\right.$ and $\left.\mathrm{CH}_{4}\right)$ using the cavity ringdown spectroscopy (CRDS) technique, Atmos. Meas. Tech., 3, 375-386, https://doi.org/10.5194/amt-3-375-2010, 2010.

Coleman, D. D., Liu, C.-L., Hackley, K. C., and Pelphrey, S. R.: Isotopic identification of landfill methane, Environ. Geosci., 2, 95-103, 1995.

Crosson, E. R.: A cavity ring-down analyzer for measuring atmospheric levels of methane, carbon dioxide, and water vapor, Appl. Phys. B-Lasers O., 92, 403-408, https://doi.org/10.1007/s00340008-3135-y, 2008.

Devos, M., Patte, F., Rouault, J., Lafort, P., and Van Gemert, L.J.: Standardized Human Olfactory Thresholds, Oxford University Press, 101, 1990.

Dlugokencky, E. J., Nisbet, E. G., Fisher R., and Lowry, D.: Global atmospheric methane: budget, changes and dangers, Philos. T. R. Soc. A, 369, 2058-2072, https://doi.org/10.1098/rsta.2010.0341, 2011.

Dlugokencky, E. J., Lang, P. M., Mund, J. W., Crotwell, A. M., Crotwell, M. J., and Thoning, K.W .: Atmospheric carbon dioxide dry air mole fractions from the NOAA/ESRL Carbon Cycle Global Cooperative Network, 1968-2016, version: 2017-07-28, available at: ftp://aftp.cmdl.noaa.gov/data/trace_gases/co2/flask/ surface/ (last access: 26 February 2018), 2017.

Fisher R., Lowry, D., Wilkin, O., Sriskantharajah, S., and Nisbet, E. G.: High-precision, automated stable isotope analysis of atmospheric methane and carbon dioxide using continuous-flow isotope-ratio mass spectrometry, Rapid Commun. Mass Spectrom., 20, 200-208, https://doi.org/10.1002/rcm.2300, 2006.

Flores, E., Viallon, J., Moussay, P., Griffith, D. W. T., and Wielgosz, R. I.: Calibration strategies for FT-IR and other isotope ratio infrared spectrometer instruments for accurate $\delta^{13} \mathrm{C}$ and $\delta^{18} \mathrm{O}$ measurements of $\mathrm{CO}_{2}$ in air, Anal. Chem., 89, 3648-3655, https://doi.org/10.1021/acs.analchem.6b05063, 2017.

GAW Report No. 185: Guidelines for the measurement of methane and nitrous oxide and their quality assurance, World Meteorological Organization, Geneva, Switzerland, 2009.

GAW Report No. 269: 18th WMO/IAEA Meeting on Carbon Dioxide, Other Greenhouse Gases and Related Tracers Measurement Techniques (GGMT-2015), La Jolla, CA, USA, 2016.

Griffith, D. W. T., Deutscher, N. M., Caldow, C., Kettlewell, G., Riggenbach, M., and Hammer, S.: A Fourier transform infrared trace gas and isotope analyser for atmospheric applications, At- 
mos. Meas. Tech., 5, 2481-2498, https://doi.org/10.5194/amt-52481-2012, 2012.

Hall, B.: Calculation of expanded uncertainties for $\mathrm{CO}_{2}$, NOAA ESRL, available at: https://www.esrl.noaa.gov/gmd/ccl/ccl_ uncertainties_co2.html (last access: 25 February 2018), 2017.

Kai, F. M., Tyler, S. C., Randerson, J. T., and Blake, D. R.: Reduced methane growth rate explained by decreased Northern Hemisphere microbial sources, Nature, 476, 194-197, 2011.

Karion, A., Sweeney, C., Pétron, G., Frost, G., Hardesty, R. M., Kofler, J., Miller, B. R., Newberger, T., Wolter, S., Banta, R., Brewer, A., Dlugokencky, E., Lang, P., Montzka, S. A., Schnell, R., Tans, P., Trainer, M., Zamora, R., and Conley, S.: Methane emissions estimate from airborne measurements over a western United States natural gas field, Geophys. Res. Lett., 40, 43934397, https://doi.org/10.1002/grl.50811, 2013.

Karion, A., Sweeney, C., Kort, E. A., Shepson, P. B., Brewer, A., Cambaliza, M., Conley, S. A., Davis, K., Deng, A., Hardesty, M., Herndon, S. C., Lauvaux, T., Lavoie, T., Lyon, D., Newberger, T., Pétron, G., Rella, C., Smith, M., Wolter, S., Yacovitch, T., and Tans, P.: Aircraft-based estimate of total methane emissions from the Barnett Shale region, Environ. Sci. Technol., 49, 8124-8131, https://doi.org/10.1021/acs.est.5b00217, 2015.

Keeling, C. D.: The Concentration and Isotopic Abundances of Carbon Dioxide in Rural and Marine Air, Geochim. Cosmochim. Ac., 24, 277-298, 1961.

Mikaloff Fletcher, S. E., Tans, P. P., Bruhwiler, L. M., Miller, J. B., and Heimann, M.: $\mathrm{CH}_{4}$ sources estimated from atmospheric observations of $\mathrm{CH}_{4}$ and its ${ }^{13} \mathrm{C} /{ }^{12} \mathrm{C}$ isotopic ratios: 1 . Inverse modeling of source processes, Global Biogeochem. Cy., 18, GC4004, doi.10.1029/2004GB002223, 2004a.

Mikaloff Fletcher, S. E., Tans, P. P., Bruhwiler, L. M., Miller, J. B., and Heimann, $\mathrm{M}$.: $\mathrm{CH}_{4}$ sources estimated from atmospheric observations of $\mathrm{CH}_{4}$ and its ${ }^{13} \mathrm{C} /{ }^{12} \mathrm{C}$ isotopic ratios: 2 . Inverse modeling of $\mathrm{CH}_{4}$ fluxes from geographical regions, Global Biogeochem. Cy., 18, GC4005, doi.10.1029/2004GB002224, 2004 b.

Miles, N. L., Martins, D. K., Richardson, S. J., Lauvaux, T., Davis, K. J., Haupt, B. J., and Rella, C.: In-situ tower atmospheric methane mole fraction and isotopic ratio of methane data, Marcellus Shale Gas Region, Pennsylvania, USA, 2015-2016, Data set, available at: http://datacommons.psu.edu, from The Pennsylvania State University Data Commons, University Park, Pennsylvania, USA, https://doi.org/10.18113/D3SG6N, 2017.

Molofsky, L. J., Connor, A. A., Farhat, S. K., Wylie Jr., A. S., and Wagner, T.: Methane in Pennsylvania water wells unrelated to Marcellus shale fracturing, Oil Gas J., 109, 54-67, 2011.

Montzka, S. A., Myers, R. C., Butler, J. H., Elkins, J. W., and Cummings, S.: Global tropospheric distribution and calibration scale of HCFC-22, Geophys. Res. Lett., 20, 703-706, 1993.

Pataki, D. E., Ehleringer, J. R., Flanagan, L. B., Yakir, D., Bowling, D. R., Still, C. J., Buchmann, N., Kaplan, J. O., and Berry, J. A.: The application and interpretation of Keeling plots in terrestrial carbon cycle research, Global Biogeochem. Cy., 17, 1022, https://doi.org/10.1029/2001GB001850, 2003.

Peischl, J., Karion, A., Sweeney, C., Kort, E. A., Smith, M. L., Brandt, A. R., Yeskoo, T., Aikin, K. C., Conley, S. A., Gvakharia, A., Trainer, M., Wolter, S., and Ryerson, T. B.: Quantifying atmosphere methane emissions from oil and natural gas production in the Bakken shale region of North Dakota, J. Atmos. Res. D., 6101-6111, https://doi.org/10.1002/2015JD024631, 2016.
Pétron, G., Frost, G., Miller, B. R., Hirsch, A. I., Montzka, S. A., Karion, A., Trainer, M., Sweeney, C., Andrews, A. E., Miller, L., Kofler, J., Bar-Ilan, A., Dlugokencky, E. J., Patrick, L., Moore Jr., C. T., Ryerson, T. B., Siso, C., Kolodzey, W., Lang, P. M., Conway, T., Novelli, P., Masarie, K., Hall, B., Guenther, D., Kitzis, D., Miller, J., Welsh, D., Wolfe, D., Neff, W., and Tans, P.: Hydrocarbon emissions characterization in the Colorado Front Range: A pilot study, J. Geophys. Res., 117, D04304, https://doi.org/10.1029/2011JD016360, 2012.

Pétron, G., Karion, A., Sweeney, C., Miller, B. R., Montzka, S. A., Frost, G. J., Trainer, M., Tans, P., Andrews, A., Kofler, J. Helmig, D., Guenther, D., Dlugokencky, E., Lang, P., Newberger, T., Wolter, A., Hall, B., Novelli, P., Brewer, A., Conley, S., Hardesty, M., Banta, R., White, A., Noone, D., Wolfe, D., and Schnell, R.: A new look at methane and nonmethane hydrocarbon emissions from oil and natural gas operations in the Colorado Denver-Julesburg Basin, J. Geophys. Res.-Atmos., 119, 6836-6952, https://doi.org/10.1002/2013JD021272, 2014.

Rella, C. W., Hoffnagle, J., He, Y., and Tajima, S.: Local- and regional-scale measurements of $\mathrm{CH}_{4}, \delta^{13} \mathrm{CH}_{4}$, and $\mathrm{C}_{2} \mathrm{H}_{6}$ in the Uintah Basin using a mobile stable isotope analyzer, Atmos. Meas. Tech., 8, 4539-4559, https://doi.org/10.5194/amt-8-45392015, 2015.

Richardson, S. J., Miles, N. L., Davis, K. J., Lauvaux, T., Martins, D., Turnbull, J., and Sweeney, C.: Tower measurement network of in-situ $\mathrm{CO}_{2}, \mathrm{CH}_{4}$, and $\mathrm{CO}$ in support of the Indianapolis FLUX (INFLUX) Experiment, Elem. Sci. Anth., 5, https://doi.org/10.1525/elementa.140, 2017.

Röckmann, T., Eyer, S., van der Veen, C., Popa, M. E., Tuzson, B., Monteil, G., Houweling, S., Harris, E., Brunner, D., Fischer, H., Zazzeri, G., Lowry, D., Nisbet, E. G., Brand, W. A., Necki, J. M., Emmenegger, L., and Mohn, J.: In situ observations of the isotopic composition of methane at the Cabauw tall tower site, Atmos. Chem. Phys., 16, 10469-10487, https://doi.org/10.5194/acp-16-10469-2016, 2016.

Schwietzke, S., Sherwood, O. A., Bruhwiler, L. M. P., Miller, J. B., Etiope, G., Dlugokencky, E. J., Michel, S. E., Arling, V. A., Vaughn, B. H., White, J. W. C., and Tans, P. P.: Upward revision of global fossil fuel methane emissions based on isotope database, Nature, 538, 88-91, https://doi.org/10.1038/nature19797, 2016.

Townsend-Small, A., Marrero, J. E., Lyon, D. R., Simpson, I. J., Meinardi, S., and Blake, D. R.: Integrating source apportionment tracers into a bottom-up inventory of methane emissions in the Barnett Shale hydraulic fracturing region, Environ. Sci. Technol., 49, 8175-8182, https://doi.org/10.1021/acs.est.5b00057, 2015.

Turnbull, J., Guenther, D., Karion, A., Sweeney, C., Anderson, E., Andrews, A., Kofler, J., Miles, N., Newberger, T., Richardson, S., and Tans, P.: An integrated flask sample collection system for greenhouse gas measurements, Atmos. Meas. Tech., 5, 23212327, https://doi.org/10.5194/amt-5-2321-2012, 2012.

Vaughn, B., Miller, J., Ferretti, D. F., and White, J.: Stable isotope measurements of atmospheric $\mathrm{CO}_{2}$ and $\mathrm{CH}_{4}$, in: Handbook of Stable Isotope Analytical Techniques, 272-304, https://doi.org/10.1016/B978-044451114-0/50016-8, 2014.

Warneck P. and Williams, J.: The Atmospheric Chemist's Companion: Numerical data for use in the atmospheric sciences, Springer, https://doi.org/10.1007/978-94-007-2275-0, 2012. 
Wen, X.-F., Meng, Y., Zhang, X.-Y., Sun, X.-M., and Lee, X.: Evaluating calibration strategies for isotope ratio infrared spectroscopy for atmospheric ${ }^{13} \mathrm{CO}_{2} /{ }^{12} \mathrm{CO}_{2}$ measurement, Atmos. Meas. Tech., 6, 1491-1501, https://doi.org/10.5194/amt-6-14912013, 2013 .
Zhao, C. and Tans, P. P.: Estimating uncertainty of the WMO mole fraction scale for carbon dioxide in air, J. Geophys. Res., 111, D08S09, https://doi.org/10.1029/2005JD006003, 2006. 